\title{
Gender Differences in Human Brain: A Review
}

\author{
Zeenat F. Zaidi*
}

Department of Anatomy, Faculty of Medicine, King Saud University, Riyadh, Saudi Arabia

\begin{abstract}
Why do men and women think differently? Why do they behave differently in stressed situations? Why do women act more emotionally as compared to men? Why do men and women excel at different types of tasks? Why do boys like to play with cars and trucks and superman? These are the common questions which arise commonly in minds. The human brain is a highly complex organ. Studies of perception, cognition, memory and neural functions have found apparent gender differences. These differences may be attributed to various genetic, hormonal, and environmental factors and do not reflect any overall superiority advantage to either sex. Both sexes are equal in intelligence, but tend to operate differently. Men and women appear to use different parts of the brain to encode memories, sense emotions, recognize faces, solve certain problems and make decisions. Indeed, when men and women of similar intelligence and aptitude perform equally well, their brains appear to go about it differently, as if nature had separate blueprints. Sex differences in the brain may play a role in learning processes, language development, and progression of neurologicallybased diseases. Sex differences need to be considered in studying brain structure and function and may raise the possibility of sex-specific treatments for neurological diseases. In this article it is reviewed that how does the brain of a male look and function differently from a female's brain, and what accounts for these differences?
\end{abstract}

Keywords: Human brain, gender differences, brain aging, neurological disorders, learning.

\section{ANATOMICAL DIFFERENCES}

Several postmortem and structural neuroimaging studies in humans have shown the following morphological differences that are likely to reflect an interaction between developmental influences, experience, and hormone actions on the mature brain.

\section{Size \& Weight}

The adult human brain weighs on average about $3 \mathrm{lb}$ (1.5 $\mathrm{kg}$ ) [1] with a size of around $1130 \mathrm{~cm}^{3}$ in women and 1260 $\mathrm{cm}^{3}$ in men although there is substantial individual variation [2]. Male brains are about $10 \%$ larger than female brains and weigh $11-12 \%$ more than that of a woman. Men's heads are also about $2 \%$ bigger than women's. This is due to the larger physical stature of men. Male's larger muscle mass and larger body size requires more neurons to control them. The brain weight is related to the body weight partly because it increases with increasing height [3]. This difference is also present at birth. A boy's brain is between $12-20 \%$ larger than that of a girl. The head circumference of boys is also larger (2\%) than that of girls. However, when the size of the brain is compared to body weight at this age, there is almost no difference between boys and girls. So, a girl baby and a boy baby who weigh the same will have similar brain sizes.

\section{Brain Volume}

Sexual dimorphisms of adult brain volumes were more evident in the cortex, with women having larger volumes, relative to cerebrum size, particularly in frontal and medial

*Address correspondence to this author at the Department of Anatomy, Faculty of Medicine, King Saud University, P.O. Box 22452, Riyadh 11495, Saudi Arabia; Tel: +966-1-4781995; Mobile: +966502151924; Fax: +966-14781995; E-mail: zeenatzaidi@hotmail.com paralimbic cortices. Men had larger volumes, relative to cerebrum size, in frontomedial cortex, the amygdala and hypothalamus. There was greater sexual dimorphism in brain areas that are homologous with those identified in animal studies showing greater levels of sex steroid receptors during critical periods of brain development. These findings have implications for developmental studies that would directly test hypotheses about mechanisms relating sex steroid hormones to sexual dimorphisms in humans [4].

\section{Grey Matter vs White Matter}

Ratios of grey to white matter also differ significantly between the sexes in diverse regions of the human cortex [5]. Variations in the amount of white and grey matter in the brain remain significant [6-8]. Men have approximately 6.5 times more gray matter in the brain than women, and women have about 10 times more white matter than men do [3]. At the age of 20, a man has around 176,000 $\mathrm{km}$ and a woman, about $149,000 \mathrm{~km}$ of myelinated axons in their brains [9]. Men appear to have more gray matter, made up of active neurons, and women more of the white matter responsible for communication between different areas of the brain [10]. In women's brains, the neurons are packed in tightly, so that they're closer together. Some women even have as many as 12 percent more neurons than men do [10]. These neurons are densely crowded on certain layers of the cortex, namely the ones responsible for signals coming in and out of the brain, and these differences were present from birth [10]. When controlling for total cerebral volume, women had a higher percentage of grey matter than men, and men had a higher percentage of white matter $[6,8]$ and both gray and white matter volumes correlated with cognitive performance across sex groups. The average number of neocortical neurons was 19 billion in female brains and 23 billion in male brains, a $16 \%$ difference. In a study, which covered the 
age range from 20 years to 90 years, approximately $10 \%$ of all neocortical neurons are lost over the life span in both sexes. Sex and age were the main determinants of the total number of neurons in the human neocortex, whereas body size, per se, had no influence on neuron number [11]. Gender differences in precentral, cingulate, and anterior temporal white matter areas were also found, suggesting that microstructural white matter organization in these regions may have a sexual dimorphism [12].

\section{Hypothalamus}

Hypothalamus, where most of the basic functions of life are controlled, including hormonal activity via the pituitary gland also shows gender differences. The volume of a specific nucleus in the hypothalamus (third cell group of the interstitial nuclei of the anterior hypothalamus) is twice as large in heterosexual men as in women and homosexual men [13]. The preoptic area, involved in mating behavior, is about 2.2 times larger in men than in women and contains 2 times more cells. This enlargement is dependent on the amount of male sex hormones or androgens. Apparently, the difference in this area is only apparent after a person is 4 years old. At 4 years of age, there is a decrease in the number of cells in this nucleus in girls. The neuropil of the preoptic area is sexually dimorphic [14]. Gender-related differences were found in 2 cell groups in the preoptic-anterior hypothalamic area (PO-AHA) in human brain. Both nuclei were larger in male and appeared to be related in women to circulating steroid hormone levels [15]. The suprachiasmatic nucleus of the hypothalamus, involved with circadian rhythms and reproduction cycles, is different in shape in these two sexes. In males, this nucleus is shaped like a sphere whereas in females it is more elongated. However, the number of cells and volume of this nucleus are not different in men and women. It is possible that the shape of the suprachiasmatic nucleus influences the connections that this area makes with other areas of the brain, especially the other areas of the hypothalamus. In most hypothalamic areas that stain positively for androgen receptor (AR), nuclear staining in particular is less intense in young adult women than in men. The strongest sex difference is found in the lateral and medial mamillary nucleus [16]. The mamillary body complex is known to receive input from the hippocampus by the fornix and to be involved in cognition. In addition, a sex difference in AR staining is present in the horizontal diagonal band of Broca, the sexually dimorphic nucleus of the preoptic area, the medial preoptic area, the dorsal and ventral zone of the periventricular nucleus, the paraventricular nucleus, the supraoptic nucleus, the ventromedial hypothalamic nucleus and the infundibular nucleus. No sex differences were observed in AR staining in the bed nucleus of the stria terminalis, the nucleus basalis of Meynert and the island of Calleja [16].

\section{Anterior Commissure}

It connects several regions of the frontal and temporal lobes and is $12 \%$, or $1.17 \mathrm{~mm}^{2}$ larger in women than in men [17].

\section{Massa Intermedia}

A structure that crosses the third ventricle between the two thalami, was present in $78 \%$ of females and $68 \%$ of males. Among subjects with a massa intermedia, the structure was an average of $53.3 \%$ or $17.5 \mathrm{~mm}^{2}$ larger in females than in males. Anatomical sex differences in structures that connect the two cerebral hemispheres may, in part, underlie functional sex differences in cognitive function and cerebral lateralization [17].

\section{Cerebellum}

An area of the brain important for posture and balance, and the pons, a brain structure linked to the cerebellum that helps control consciousness, are larger in men than in women [18].

\section{Cerebral Hemispheres}

According to the majority of studies, men possess larger cerebra than women of the same age and health status, even if the body size differences are controlled statistically. Male brains were larger than female brains in all locations, though male enlargement was most prominent in the frontal and occipital poles, bilaterally [19]. The male differentiated brain has a thicker right hemisphere. This may be the reason males tend to be more spatial, and mathematical. The left hemisphere, which is important to communication, is thicker in female oriented brains.

\section{Cerebral Cortex}

Men have 4\% more neurons than women, and about 100 grams more of brain tissue. Women have a more developed neuropil, or the space between cell bodies, which contains synapses, dendrites and axons. This may explain why women are more prone to dementia (such as Alzheimer's disease) than men, because although both may lose the same number of neurons due to the disease, in males, the functional reserve may be greater as a larger number of nerve cells are present, which could prevent some of the functional losses [20]. In the temporal neocortex, a key part which is involved in both social and emotional processes and memory, men had a one third higher density than women of synapses, and had more brain cells, though the excess was slight compared with the excess in the number of synapses. Sexual dimorphism has been reported in the cortical volume of the Wernicke and Broca areas [21], as well as in the frontal and medial paralimbic cortices [5, 19, 22, 23]. Differences have been reported in the thickness and density of the grey matter in the parietal lobes [19] in the density of neurons $[10,11,20,24]$ and in the complexity of the dendritic arbors as well as in the density of dendritic spines in several cortical areas [25]. In female brains, the cortex is constructed differently, with neurons packed more closely together in layers 2 and 4 (which form the hard wiring for signals coming into the brain) of the temporal lobe, and in layers 3, 5 and 6 (which carry the wiring for outbound signals) of the prefrontal cortex [10]. Widespread areas of the cortical mantle are significantly thicker in women than in men [26]. Studies have shown greater cortical thickness in posterior temporal and inferior parietal regions in females relative to males, independent of differences in brain or body size. Age-by-sex interactions were not significant in the temporoparietal region, suggesting that sex differences in these regions are present from at least late childhood and then are maintained throughout [19]. In a study it is shown that men have a significantly higher synaptic density than 
women in all cortical layers of the temporal neocortex [27]. Differences in brain anatomy have included the length of the left temporal plane, which is usually longer than the right. The sex differences in cellularity of the planum temporale involved an $11 \%$ larger density of neurons in several cortical layers of females, with no overlap between males and females [10].

\section{Orbitofrontal to Amygdala Ratio (OAR)}

The ratio between the orbitofrontal cortex, a region involved in regulating emotions, and the size of the amygdala, involved in producing emotional reactions, was significantly larger in women than men. One can speculate from these findings that women might on average prove more capable of controlling their emotional reactions. Women have larger orbital frontal cortices than men, resulting in highly significant difference in the ratio of orbital grey to amygdala volume. This may relate to behavioral evidence for sex differences in emotion processing [28].

\section{Limbic Size}

Females have a more acute sense of smell, and on average, have a larger deep limbic system including hippocampus [4] and anterior commissure, a bundle of fibers which acts to interconnect the two amygdales [17], than males. Due to the larger deep limbic brain women are more in touch with their feelings, they are generally better able to express their feelings than men. They have an increased ability to bond and are connected to others. On the other hand larger deep limbic system leaves a female somewhat more susceptible to depression, especially at times of significant hormonal changes such as the onset of puberty, before menses, after the birth of a child and at menopause. Women attempt suicide three times more than men [29].

\section{Corpus Callosum}

A large tract of neural fibers that allows the free flow of communication between both hemispheres of the brain is larger in women, compared to men $[8,30]$. The larger corpus callosum allows more transmissions between the two hemispheres. Thus women use both hemispheres creating more synapses between the two sides of the brain. Although this discovery has been challenged in a volumetric study of the corpus callosum in Korean people in their 20s and 40s. It was shown that Korean men have larger corpus callosum as compared to women. There was no significant difference in corpus callosum volume between 20 s and 40 s. There was a positive relationship between body weight and corpus callosum for $20 \mathrm{~s}$, but not for 40 s [31]. In another study a dramatic difference in the shape of corpus callosum was observed but there was no conclusive evidence of sexual dimorphism in the area of the corpus callosum or its subdivisions. The caudal portion of corpus callosum, the splenium was more of bulbous shaped in females and more tubular shaped in males. The maximum width of splenium was significantly greater in females than in males [5]. It has been reported that there is significant rightward asymmetries of callosal thickness predominantly in the anterior body and anterior third of the callosum, suggesting a more diffuse functional organization of callosal projections in the right hemisphere. Asymmetries were increased in men, supporting the assumption of a sexually dimorphic organization of male and female brains that involves hemispheric relations and is reflected in the organization and distribution of callosal fibers [32]. In Magnetic resonance imaging study, callosal measurements showed no significant effects of sex or handedness, although subtle differences in callosal shape were observed in anterior and posterior regions between males and females and surface variability was increased in males [32]. It was found that in men the size of corpus callosum is related to handedness. The more left-handed a person was, the bigger the corpus callosum he had. Among women there was no difference between right-handers and left-handers [33].

\section{Inferior-Parietal Lobule (IPL)}

It is significantly larger in men than in women [34]. More specifically, the left side IPL is larger than the right in men. In women, this asymmetry is reversed, although the difference between left and right sides is not as large as in men. This is the same area that was shown to be larger in the brain of Albert Einstein, as well as in other physicists and mathematicians [35]. It seems that the IPL correlates with the mathematical ability. The IPL lets the brain process input from the senses and aids in selective attention and perception. Studies have shown that the right IPL is linked to understanding spatial relationships and the ability to sense relationships between body parts [35]. The left on the other hand, is linked with perception of time and speed, and the ability to rotate 3-D figures in the brain. In general, the IPL allows the brain to process information from senses and help in selective attention and perception (for example, women are more able to focus on specific stimuli, such as a baby crying in the night).

\section{Straight Gyrus (SG)}

A narrow band at the base of the frontal lobe, involved in social cognition and interpersonal judgment is about $10 \%$ bigger in women than in men [36] (men's brains are about $10 \%$ larger than women's brains, so measures were proportional). In addition, the size of the SG also correlated with a test of social cognition, so that people who scored higher in interpersonal awareness, male or female, had larger SGs. A similar study in children between 7 and 17 years of age showed different results. The SG was larger in boys as compared to girls. And this time, a smaller SG correlated with better "interpersonal awareness"- the opposite of the results were seen in adults. This could be due to a reduction in grey matter volume, or pruning, which generally happens to girls' brains two years earlier than boys'. There does seem to be a relationship between SG size and social perception and femininity. Higher degrees of femininity were shown to be correlated with greater SG grey matter volume and surface area [36].

\section{Hippocampus}

Sex differences exist in every brain lobe, including in many 'cognitive' regions such as the hippocampus, amygdala and neocortex [37]. Extensive evidence demonstrates that male and female hippocampi differ significantly in their anatomical structure, their neuroanatomic make-up and their reactivity to stressful situations [38]. Imaging studies consistently show that the 
hippocampus is larger in women than in men when adjusted for total brain size [4].

\section{Amygdala}

A rapidly growing body of evidence also documents the sexually dimorphic nature of the human amygdala [39, 40]. It is significantly larger in men than in women adjusted for total brain size [4]. Sex differences also exist in its structural relationship with the rest of the brain. In a study of a large sample of men and women, the patterns of covariance in the size of many brain structures were 'remarkably consistent' between men and women, except the amygdala, in particular, the left hemisphere amygdala, which showed several marked sex differences [41]. Magnetic resonance imaging (MRI) studies of the normally developing brain in childhood and adolescence showed that after correction for overall brain volume the caudate is relatively larger in girls, and the amygdala is relatively larger in boys [42]. The posterodorsal nucleus of the medial amygdala (MePD) has a greater volume in male rats than in females, but adult castration of male rats causes the volume to shrink to female values within four weeks, whereas androgen treatment of adult females for that period enlarges the MePD to levels equivalent to normal males. It was demonstrated that adult hormone manipulations can completely reverse a sexual dimorphism in brain regional volume in mammals. The extent of the MePD sexual dimorphism in rats in quite comparable to reported sexual dimorphisms in the human brain $[10,11,43-46]$ and therefore supports the possibility that sexual dimorphisms of the human brain are caused solely by circulating steroids in adulthood. In addition, the regions of the brain with which the amygdala communicates while a subject is at rest are different in men and women. In men, the right amygdala is more active and shows more connectivity with brain regions such as the visual cortex and the striatum. Conversely, in women, the left amygdala is more active and is connected to regions such as the insular cortex and the hypothalamus. Many brain areas communicating with the amygdala in men are engaged with and responding to the external environment. For example, the visual cortex is responsible for vision, while the striatum coordinates motor actions. Conversely, many regions connected to the left-hemisphere amygdala in women control aspects of the environment within the body. Both the insular cortex and the hypothalamus, for example, receive strong input from the sensors inside the body. Several studies now report sex influences on amygdala function, including in the context of its well-known role in memory for emotional events. Evidence from animal research documents that the amygdala can modulate the storage of memory for emotional events, and does so through interactions with endogenous stress hormones released during stressful events [47]. This amygdala/stress hormone mechanism provides an evolutionarily adaptive way to create memory strength that is, in general, to memory importance. Both lesion and imaging studies have confirmed this conclusion in humans [48]. However, imaging studies have also revealed a sexrelated hemispheric lateralization of amygdala function in relation to memory for emotional material. Specifically, the studies consistently indicate a preferential involvement of the left amygdala in memory for emotional material (generally visual images) in women, but a preferential involvement of the right amygdala in memory for the same material in men [49-51]. In an intriguing parallel with the studies in humans, it was reported that stimulation of the right but not the left hemisphere amygdala modulates memory storage in male rats [52]. There is a distinct hemispheric relationship with sex in regards to the amygdala's function in memory. Preferential activation occurred in the left amygdala in women and in the right amygdala in men. This implies sex-specific hemispheric lateralization of amygdala function, and possibly different ways of processing emotionally arousing memories. This hemispheric lateralization was also present in resting conditions, indicating a fundamental sex difference in how the amygdala functions [53].

\section{Visual Processing and Language Memory Area}

The regions of the brain that play a key role in visual processing and in storing language and personal memories appear to differ between the sexes at the microscopic level. The frontal and the temporal areas of the cortex are more precisely organized in women, and are bigger in volume [54]. The density of synapses in the temporal neocortex was greater in men than in women. Fewer synapses to other regions may represent increasing specialization of the temporal cortex for language processing in females, and this may be related to their overall better performance on language tasks [27]. Sexes use different sides of their brains to process and store long-term memories [49] and a particular drug, propranolol, can block memory differently in men and women [55].

\section{Areas for Speech}

The two major areas related to speech, Broca, in the dorsolateral prefrontal cortex, Wernicke, in the superior temporal cortex were significantly larger in women. MRI studies showed that women had $23 \%$ in Broca's area, and $13 \%$ in Wernicke's area, more volume than men [45]. There is also a difference between men and women as to which part of the left hemisphere is responsible for speech and hand movements. In another study, the volume of the Wernicke's area was $18 \%$ larger in females compared with males, and the cortical volume of the Broca's area in females was $20 \%$ larger than in males [56]. In women, the frontal region is more important than the area at the back, so problems with speech are more likely to happen if the front part of the left hemisphere is damaged. In men, the areas contribute more equally, but if anything in the back part, especially the parietal region, is more important. The brains of women process verbal language simultaneously in the two sides (hemispheres) of the frontal brain, while men tend to process it in the left side only [57]. Studies have showed both that areas of the brain associated with language work harder in girls than in boys during language tasks, and that boys and girls rely on different parts of the brain when performing these tasks [58]. Females use the posterior temporal lobes more bilaterally during linguistic processing of global structures in a narrative than males do [59]. fMRI on a conventional scanner for determining the anatomic substrate of language between subjects and between sexes showed activation changes in the left prefrontal cortex and right cerebellum and significantly decreased responses were seen 
in the posterior cingulate and over an extensive area of medial and dorsolateral parietal and superior temporal cortices. The male cohort showed a slight asymmetry of parietal deactivation, with more involvement on the right, whereas the female cohort showed a small region of activation in the right orbitofrontal cortex [60]. The male brain has its vocabulary making power seated only in the left hemisphere enabling him to develop a large vocabulary. The female brain becomes more proficient in the vocabulary she already has using her emotions and feelings for others to aid in the production of language.

\section{Emotions}

Male oriented brains, hardly express feelings. It is due to the use of the right hemisphere only. Male brains separate language, in the left, and emotions in the right, while the female's emotions are in both hemispheres. It helps explain why the male brain has a hard time expressing its feelings [54].

\section{Thinking}

Men seem to think with their grey matter, which is full of active neurons. Women think with the white matter, which consists more of connections between the neurons. In this way, a woman's brain is a bit more complicated in setup, but those connections may allow a woman's brain to work faster than a man's [10]. The parts of the frontal lobe, responsible for problem-solving and decision-making, and the limbic cortex, responsible for regulating emotions, were larger in women. In men, the parietal cortex, which is involved in space perception, and the amygdala, which regulates sexual and social behavior, was large [61]. Men and women differ in accessing different sections of the brain for the same task. In one study, men and women were asked to sound out different words. Men relied on just one small area on the left side of the brain to complete the task, while the majority of women used areas in both sides of the brain [62]. However, both men and women sounded out the words equally well, indicating that there is more than one way for the brain to arrive at the same result.

\section{Neural Networks}

Numerous studies report sex differences in neural activity despite no behavioral difference between the sexes. For example, Piefke et al. [63] examined the neural correlates of retrieval of emotional, autobiographical memories in men and women. Memory performance did not differ between the sexes, nor did the degree of emotion induced by retrieval. However, brain regions associated with retrieval in the two sexes differed significantly. In another study, the neural correlates of naming images were examined. Men and women performed the task equally well, but the patterns of brain activity associated with their performance differed significantly [64]. The cerebral network involved in semantic processing is significantly affected by sex and sex steroid hormones [65]. In performing a visuospatial abilities task and a phonological task, women and men showed no performance differences in accuracy but showed different brain activation patterns. Males exhibited more left-sided brain activation during the phonological task and greater bilateral activity during the visuospatial task. Females showed greater bilateral activity during the phonological task and had more right-sided brain activation during the visuospatial task [66]. Men outperformed women on a mental rotation task, and women outperformed men on a verbal fluency task. Comparable brain activation occurred in association with mental rotation and verbal fluency function, but with differential performance [67]. Women perform better on some phonological tasks and men on spatial tasks. ROI-based analysis documented the expected left-lateralized changes for the verbal task in the inferior parietal and planum temporal regions in both men and women, but only men showed right-lateralized increase for the spatial task in these regions. Image-based analysis revealed a distributed network of cortical regions activated by the tasks, which consisted of the lateral frontal, medial frontal, mid-temporal, occipitoparietal, and occipital regions. The activation was more left lateralized for the verbal and more right for the spatial tasks, but men also showed some left activation for the spatial task, which was not seen in women. Increased task difficulty produced more distributed activation for the verbal and more circumscribed activation for the spatial task [68].

\section{Lateral Ventricle}

3-Tesla magnetic resonance imaging (MRI), including diffusion tensor imaging (DTI) in unsedated healthy newborns showed differences in male and female brains. The left ventricle was significantly larger than the right; females had significantly larger ventricles than males [69]. There was significant ventricular asymmetry at birth, with the left ventricle being larger than the right. This ventricle asymmetry is present in older children [46] and indicates that lateralization of the brain is present at birth. Interestingly, female newborns had larger lateral ventricles than males, even in the face of similar intracranial volumes and birth weights. Studies in older children have found no gender difference [46] or that males have larger ventricles than females [70].

\section{FUNCTIONAL DIFFERENCES}

'The female is softer in disposition, is more mischievous, less simple, more impulsive and more attentive to the nurture of the young...The fact is, the nature of man is the most rounded off and complete' (Aristotle).

Men and women differ not only in their physical attributes and reproductive function but also in many other characteristics, including learning processes, language development, and the way they solve intellectual problems. Sex differences have been observed in cognitive functioning and brain structure. These differences may be attributed to various genetic, hormonal, and environmental factors and do not reflect any overall superiority advantage to either sex. It is well known that men and women display different capacities in certain cognitive functions that are unrelated to differences in the general level of intelligence. Witleson [10] concluded that people use their 'preferred cognitive strategy' based on the faculties they have. It is suggested that men and women may tend to think in different ways, but every individual thinks in his, or her, individual way. Men and women appear to use different parts of the brain to encode memories, sense emotions, recognize faces, solve certain problems and make decisions. It is well known that emotional development and cognitive abilities [71] 
particularly visuospatial skills, differ between males and females [72-74]. It has been shown that the two hemispheres in some cognitive tasks function differently in the male and the female brain [57, 75, 76]. Ray et al. [77] found that for high spatial ability males greater right hemispheric activation was associated with better spatial problem solving. No marked relationship between lateralization and cognitive performance was found in the female. Males have consistently shown an advantage in visual-spatial abilities, such as aiming at stationary or moving targets, as well as throwing and intercepting projectiles [76]. Males also excel at quantitative problem solving, and mental rotation, or tasks involving the underlying cognitive processes of maintaining and manipulating a visual image in working memory [78].

Sex differences have been observed in functioning as well as neurobehavioral measures. Men and women differ in emotion processing, including perception, experience and expression, most notably reflected in greater male aggression. Studies revealed that males are more aggressive than females, as young males engage in more rough-andtumble play than females and that females are more nurturing. There is also a sex difference in aggression. Males tend to show far more "direct" aggression such as pushing, hitting and punching. Females tend to show more "indirect" (or "relational", covert) aggression [79]. The most striking differences appear in the way men and women estimate time, judge speed of things [35], carry out mental mathematical calculations, orient in space and visualize objects in three dimensions and the way their brains process language information, emotion, cognition., etc. Men and women display different capacities in certain cognitive functions that are unrelated to differences in the general level of intelligence. The most consistently reported differences relate to spatial and language abilities, and whereas men excel in mental rotation and spatial perception, women perform better in verbal memory tasks, in verbal fluency tasks, and in the speed of articulation $[76,80]$.

According to empathizing-systemizing (E-S) theory [81], the female brain is predominantly hard-wired for empathy, and that the male brain is predominantly hard-wired for understanding and building systems. Empathizing is the drive to identify another person's emotions and thoughts, and to respond to these with an appropriate emotion. The empathizer intuitively figures out how people are feeling, and how to treat people with care and sensitivity. Systemizing is the drive to analyze and explore a system, to extract underlying rules that govern the behavior of a system; and the drive to construct systems. The systemizer intuitively figures out how things work, or what the underlying rules are controlling a system. Females tend to be higher than males in empathy, verbal skills, social skills and security-seeking, among other things, while men tend to be higher in independence, dominance, spatial and mathematical skills, rank-related aggression, and other characteristics [82]. Girls from 1 year old show greater concern through more sad looks, sympathetic vocalizations and comforting. Women also show more comforting, even to strangers, than men do [83]. More women value the development of altruistic, reciprocal relationships, which by definition require empathizing. In contrast, more men value power, politics, and competition [84].
There are some things boys tend to be better at than girls and vice versa. There is a skill superiority already built into general male and female brain development. Boy's occipital lobes are more developed, allowing them to see better in brighter light. Boys also require more movement when learning. The female brain is more decentralized. Female brains have a greater ability to multitask because their cerebrum is more active. Women use a variety of parts of their brains when they do a single task. The female brain is more integrated with more complex connections between both hemispheres. Thought and emotion are more complex than in the male brain. Women can think logically and emotionally at the same time. Other tests have claimed that females are superior in language, verbal fluency, speed of articulation and grammar, also arithmetic calculation. Their perceptual speed, for example in matching items is better, and so is their manual precision. Males are reckoned to be better at tasks that are spatial in nature, such as maze performance and mental rotation tasks, mechanical skills, mathematical reasoning and finding their way through a route. Women generally can recall lists of words or paragraphs of text better than men [85]. Imaging studies of the living brain indicate that in women neurons on both sides of the brain are activated when they are listening, while in men neurons on only one side of the brain are activated [56, 86]. Men and women appear to process single words similarly, but in the interpretation of whole sentences, women use both sides of the brain while men use one side [87]. In early childhood females are more advanced than males in language and social development, and by middle childhood males outperform females in selected tasks of spatial abilities [88]. Boys, however, appear to have a higher prevalence of developmental and learning disabilities. This may be due to the fact that male foetuses require the maintenance of higher numbers of nerve cells in the cerebral cortex than female foetuses and early damage to the male developing brain could result in higher losses of needed neurons [89]. Extremely low birth-weight and premature infants, especially males, are at greater risk of perinatal brain injury and later neurological and cognitive impairment and learning difficulties [90]. Berk [88], and Arnold [91] suggest the origin of these differences may in part reflect differences in brain lateralization and maturation arising from prenatal exposure to gonadal steroids. For term infants the early rise in testosterone levels in males is completed by approximately 16 weeks of intrauterine life. Between then and the surge in testosterone levels at birth, the foetal level of androgens are similar in males and females [92]. The brain has androgen receptors within neurons [93], and though the situation in human infants is uncertain, in canaries testosterone exposure is responsible for gender differences in later programmed cell death [94]. Brothwood et al. [95] in a study of 188 infants weighing less than 1500 $\mathrm{gm}$ at birth, reported females at 1 and 2 years being more advanced than males in overall cognitive ability as well as personal social and language development. A study in extremely low birth weight (ELBW) infants indicate that female ELBW children were superior to male ELBW children by approximately two to four GQ points at 2 years of age. This superiority in ability was predominantly due to female children being more advanced in the area of speech and language and personal social skills [96]. Studies have 
shown that men use the left side of their brains when they listen to someone speaking, whereas women use both sides. This means that women process the information they hear from human speech in a different way than men do [55]. Male and female brains work differently -at least under stress. Men responded with increased blood flow to the right prefrontal cortex, responsible for "fight or flight.", and a decreased blood flow to the left orbitofrontal cortex. Women had increased blood flow to the limbic system, which is also associated with a more nurturing and friendly response. The changes in the brain during stress response also lasted longer in women. The neural response among the men was associated with higher levels of cortisol, whereas women did not have as much association between brain activation to stress and cortisol changes. As a whole, girls outperform boys in the use of language and fine motor skills until puberty. Boys generally demonstrate superiority over female peers in areas of the brain involved in math and geometry [97]. Females tend to think more observantly and women tend to be more observant. Men tend to be more logical emotionally. They tend to put importance on their feelings and observations about a situation.

Women are better than men in human relations, recognizing emotional overtones in others and in language, emotional and artistic expressiveness, esthetic appreciation, verbal language and carrying out detailed and pre-planned tasks. For example, women generally can recall lists of words or paragraphs of text better than men [85]. Men generally do better in performing activities that require spatial skills or ability to mentally rotate an image in order to solve a problem, like navigating directions. Men navigate by using abstract concepts such as north and south or distances. Women navigate by talking about landmarks and things that can be seen or heard. Men use their left hippocampus regions when they navigate. However, women use the cerebral cortex [55]. When negotiating a virtual reality maze, both men and women use the right hippocampus to figure out how to exit. However, men also use the left hippocampus for this task, while women do not, and women also use the right prefrontal cortex, while men do not [98].

While the brain allows us to think, it also drives our emotions. The ability to identify and control emotions varies between sexes. Women are faster and more accurate at identifying emotions [99]. Women, as a whole, may also be better than men at controlling their emotions. Studies have shown women to be more adept than men at encoding facial differences and determining changing vocal intonations. Sections of the brain used to control aggression and anger responses are larger in women than in men [99]. Male brains separate language, in the left, and emotions in the right, while the female's emotions are in both hemispheres. This helps explain why the male brain has a hard time expressing its feelings. Women use language skills to their advantage. Females use language more when they compete. They gossip, manipulate information. Women also use language to build relationships. Women pause more, allow the other friend to speak more, and offer facilitative gestures [54]. Men's and women's brains fire differently when they are planning to reach for something so rehabilitation after brain injuries such as stroke may need to be tailored to the sex of the person. A fMRI study showed that in female there are three major areas involved in visually guided movement such as using a computer mouse or driving a car, and they showed activity on both sides of the brain. While male brain lit up on both sides only for the most complex exercises [100]. It has been reported that differences exist in functional brain organization between sexes, and sex hormones may play an important role in organizing brain functioning in response to certain tasks in women [101] and these differences in brain lateralization may be task-dependent $[102,103]$. Certain studies using spatial abilities tests showed, men performed better than women. However, women showed a more homogenous pattern of memory, performing similarly on both tests [104]. In a spatial test in a virtual landscape men more accurately located a target than women, both with and without the presence of directional cues. Although the performance gap lessened when both sexes were provided positional cues, men still showed an advantage in the test [105].

Though there are no disparities in general intelligence between the sexes there are differences in brain structure. As for intelligence, average IQ scores are the same for both men and women. Men have nearly 6.5 times the amount of grey matter related to general intelligence compared with women, whereas women have nearly 10 times the amount of white matter related to intelligence compared to men The study also found that the grey matter driving male intellectual performance is distributed throughout the brain. Men think more with their gray matter, and women think more with white [3]. After matching the brain specimens to the intellectual qualities of their owners, it was discovered that differences in the size of the corpus callosum were linked to IQ scores for verbal ability, but only in women and that memory was linked to how tightly neurons were packed, but only in men These findings suggest that human evolution has created two different types of brains designed for equally intelligent behavior [106]. There is not a clear correlation between the intelligence with the size of the brain. The intelligence of humans with brains weighing as little as half the average may be normal or even above average [107]. IQ is positively correlated with total cerebral volume in children, in particular, with the volume of cortical grey matter in the prefrontal region of the brain. Subcortical grey matter also contributes to the variance in IQ, although to a lesser extent than cortical grey volume. Quantitative knowledge of the developing human brain will play an increasingly greater role in improving sensitivity and specificity in the interpretation of brain abnormalities in patients within the clinical environment, as well as in groups of children with suspected brain dysfunction [108].

\section{BIOCHEMICAL DIFFERENCES}

Human brain is chemically heterogeneous in regard to sex, age, and brain region. These chemical heterogeneities are region specific and are seen mainly in the sensorimotor cortex and orbital frontal cortex. The sensorimotor cortex is involved in sensory and motor processing, perception, and motor execution and the prefrontal cortex is implicated in working memory, planning and sequencing of behavior, language and attention (dorsolateral part), and decisionmaking processes (ventromedial or orbital part) [109-114]. Increased level of $\mathrm{N}$-acetyl aspartate (NAA) is found in female sensorimotor cortex [115]. NAA is localized within neurons and is involved in synaptic processes and can be 
considered a neuronal and axonal marker [116, 117]. Subsequent breakdown of NAA leads to aspartate, which is an excitatory amino acid neurotransmitter. Increased level of Glc spectra was detected in female orbital frontal cortex [115].

Functional brain imaging studies (single-photon emission tomography and positron emission tomography (PET)) indicate sex differences in brain metabolism, particularly in global and regional cerebral blood flow and glucose consumption [75, 118-124]. Cognitive activity resulted in increased flow of blood to the cerebral hemispheres. The increase was shown to be greater to the left hemisphere for a verbal task and to the right hemisphere for a spatial task. The direction and degree of hemispheric flow asymmetry were influenced by sex and handedness, females and left-handers having a higher rate of blood flow per unit weight of brain $[118,125]$. Usually by the sixth decade, men and women show similar flow rates [126]. Men have relatively higher glucose metabolism than women in temporal-limbic regions and cerebellum and relatively lower glucose metabolism in cingulate regions. In both sexes, metabolism was relatively higher in left association cortices and the cingulate region and in right ventro-temporal limbic regions and their projections [75].

PET receptor characterization and pharmacological studies showed the ability to detect sex differences for some neurotransmitters and receptors. Several studies have documented sex differences in the serotonin system. Sex differences have been reported in the levels of serotonin metabolites in post-mortem tissue [127] and in the number of cells in the human raphe nucleus [128]. Serotonergic mechanisms are involved in gender-related behaviors and psychiatric conditions like aggression, eating disorders, depression, impulsivity or suicide. The CNS serotonin system behaves differently in men and women in many important ways [129-133]. The mean rate of serotonin synthesis in normal males is $52 \%$ higher than in normal females [129]. Significantly higher type-2 serotonin receptor binding capacity is found in men than in women, especially in the frontal and cingulate cortices [134]. Women have a greater number of the most common serotonin receptors than men, and have lower levels of the protein that transports serotonin back into the nerve cells that secrete it. Compared to men, women had significantly higher $5-\mathrm{HT}_{1 \mathrm{~A}}$ receptor and lower 5-HTT binding potentials in a wide array of cortical and subcortical brain regions. In women, there was a positive correlation between $5-\mathrm{HT}_{1 \mathrm{~A}}$ receptor and 5-HTT binding potentials for the region of hippocampus. Sex differences in $5-\mathrm{HT}_{1 \mathrm{~A}}$ receptor and 5-HTT $\mathrm{BP}_{\mathrm{ND}}$ may reflect biological distinctions in the serotonin system contributing to sex differences in the prevalence of psychiatric disorders such as depression and anxiety [135].

Evidence also exists for sex differences in many neurotransmitter systems within the hippocampus, including the adrenergic, serotonergic, cholinergic, corticosterone, benzodiazepine and cholecystokinin systems [38]. For example, receptor affinity of glucocorticoids in females is half than in males, a difference that does not depend on circulating sex hormones [136]. Sex differences are also reported in biochemical pathways pertaining to dopamine, and the interactions between them [137-140]. Compared with men, women have higher striatal $\left[{ }^{18} \mathrm{~F}\right]$ fluorodopa uptake, suggestive of greater presynaptic dopamine synthesis [141], and a lower D2 receptor affinity [142]. Women also have lower amphetamine-stimulated dopamine release [143], and a greater dopamine transporter uptake [144]. Thus, compared with men, women appear to have elevated basal, but decreased stimulated, striatal dopamine levels. An early study identified sex differences in monoamine content in the human brain. Levels of monoamine oxidase were significantly higher in several brain regions in women than in men [145]. Studies of postmortem tissues have shown women to have higher mean brain monoamine oxidase activity than men [146].

A comprehensive study of the localization of ER- $\beta$ immunoreactivity and differences in the brains of adult male and female rats showed an obvious difference of estrogen receptor ER- $\beta$ immunoreactivity between male and female rats, and its intracellular distribution also showed a sex difference. Estrogen may exert its function in different brain regions in a gender-specific manner [147]. Gender differences have also been detected in opioid sensitivity and opioid-hormone interactions in humans [148, 149] and in analgesic responses to $\mathrm{m}$-and $\mathrm{k}$-like opioids [150]. A PET scan investigation revealed significantly different levels of opioid receptor binding in several brain regions in men $v s$ women, including the amygdala and thalamus [149].

Sex differences in the genetic epidemiology and clinical features of psychiatric disorders are well recognized. Catechol-O-methyltransferase (COMT), which metabolizes catechol compounds, notably dopamine, is one of the genes that may well contribute to the genetic basis for sexual dimorphisms in human brain, behavior, and its disorders [151]. Genetic associations between COMT and various psychiatric phenotypes frequently show differences between men and women and may contribute to, its differential involvement in psychiatric disorders in men and women. The low-activity of Met158 allele was associated with obsessivecompulsive disorder (OCD) in men, but not in women [152, 153].

\section{DIFFERENCES IN BRAIN MATURATION \& AGING}

Male and female brains are known to develop differently, and even to age differently at the neuroanatomical level. Distinct differences in the male and female brains were noted in the developing fetus between 16-36 weeks of pregnancy. The corpus callosum showed a thicker measurement in female fetuses than in male fetuses suggesting sex dimorphism of human corpus callosum and raise the possibility that prenatal sex hormones may play a role in determining callosal development [154]. The brains of men and women are indeed different from birth. Yet the differences are subtle. They might be found only among the synapses in brain structures responsible for specific cognitive abilities [10].

Although the brain and its regions become well differentiated during fetal development, much of the maturational process occurs after birth. MRI analysis of a sample of children with the age range of 7-11 years and compared to adults, suggests earlier maturation of females [155]. Adolescent brain development appears to be different in males and females. Males age 6-17 years have been 
shown to display more prominent age-related decreases in gray matter (the part of the brain that allows us to think) and increases in white matter (which transfers information between distant regions) than females. These changes in brain composition appear to be linked to developmental processes in which nerve cell connections are "pruned" in gray matter and made more efficient (myelinated) in white matter. The more dramatic changes seen in males may be related to the different effects of estrogen and testosterone on the brain [156].

Adolescents' brains undergo a substantial "pruning" or reduction in gray matter volume during adolescence, which happens about two years earlier in girls, compared to boys. Girls also reach puberty two years earlier than boys. It is well-established that prefrontal cortex, a part of the brain that relates to planning ahead and knowing the consequences of one's actions, develops earlier in girls compared to boys. Areas of the brain involved in language and fine motor skills (such as handwriting) mature about six years earlier in girls than in boys. It has been concluded that when it comes to mathematics, the brain of a 12-year-old girl resembles that of an 8-year-old boy.

Brain volume decreased with age among men, but hardly at all among women. Moreover, those anatomical changes appeared to be closely tied to a gradual decline in mental performance in men. "There is something going on in the male brain that is not going on in the female brain" [10]. Age-related reductions in brain volume are sexually dimorphic, lateralized, and region specific. Greater decrements in brain volume occur with age in the frontal lobe than in the temporal lobe and in both regions it is greater in men than in women [157]. Total number of neurons in human neocortex was reduced by $10 \%$ over the life span in both sexes, and sex and age were the main determinants of the total number of neurons in neocortex that was determined using a modern stereological method [11]. Some brain regions, all frontal and temporal cortical regions and some basal ganglia structures show age-associated volume decline and men undergo more accelerated cerebral aging than women. The associations of age with reduced grey matter is generally less prominent in subcortical regions. These are stronger for men than women in the dorsolateral prefrontal cortex [28]. Age-related loss of neurons $(18-20 \%)$, which was mirrored in volume losses, was found to occur in the primary visual cortex in both sexes in all layers except IV. Males, but not females, also lost neurons (15\%) from layer V/VI of the ventral medial prefrontal cortex and showed an overall decrease in volume of this region. In contrast, dorsal medial prefrontal cortex showed no age-related changes. The effects of aging clearly differ among regions of the rat brain and to some degree, between the sexes [158]. Women are less vulnerable to agerelated changes in mental abilities, whereas men are particularly susceptible to aging effects on left hemispheric functions [159].

\section{CAUSES}

Sexual differentiation of the human brain is a multifactorial process. The differences are not thought to be only consequence of the influence of sex hormones on brain organization during development but also of genetic factors $[2,160,161]$.

\section{Genetic Factors}

From conception until the eighth week of gestation, men and women are almost exactly the same. The only difference is at the chromosomal level, deep inside the embryo's cells. One pair of chromosomes determines whether the person is male or female. Except in the case of extremely rare abnormalities, a person with two $\mathrm{X}$ chromosomes is female, and a person with one $\mathrm{X}$ chromosome and one $\mathrm{Y}$ chromosome is male. Several studies have provided evidence that some sex differences do occur very early during development, before fetuses are exposed to endogenous sex steroid hormones. The genetic makeup of individuals tends to dictate physiological differences. Male and female brain cells carry a different complement of sex chromosome genes and are influenced throughout life by a different mix of gonadal hormones. It is suggested that brain cells that differ in their genetic sex are not equivalent, and that difference may contribute to sex differences in brain function. XX and $X Y$ cells differentiate even before they are influenced by gonadal hormones, and even if they are exposed to similar levels of gonadal steroids. Genes on the sex chromosomes probably determine the gender (sexually dimorphic phenotype) of the brain in two ways: by acting on the gonads to induce sex differences in levels of gonadal secretions that have sex-specific effects on the brain, and by acting in the brain itself to differentiate XX and XY brain cells [162]. A study in mice showed that sex chromosome genes contribute directly to the development of a sex difference in the brain [163]. Sexual identity is hard-wired and is determined before a person is even born. In a study, researchers performed two different genetic tests comparing the production of genes in male and female mice brains before the animal developed sex organs. They discovered 54 genes that were produced in different amounts in male and female brains--independent of hormonal influences. Of those 54 genes, 18 were produced in higher quantities in the male brain and 36 were found in higher quantities in the female brain [164]. Sex differences in dopaminergic neurons in rat fetuses had been demonstrated on day 14.5 post coitum (dpc) [165], while genomic study by [164] identified over 50 genes whose expression differed between male and female mouse brain on day $10.5 \mathrm{dpc}$ well before gonads start to produce sex steroids. A study by Smith-Bouvier et al. [166], strongly suggests that sex chromosomes also play an important role in development of the differences between sexes in incidence and progression of autoimmune diseases. Animal experimental studies showed evidence for primary genetic control of sexual differentiation that does not involve sex hormones. Results obtained from cultures of embryonic rat brain indicate that dopaminergic neurons may develop morphological and functional sex differences in the absence of sex steroids [167]. Candidates for such hormoneindependent effects are those genes located on the nonrecombining part of the $\mathrm{Y}$ chromosome and believed to be involved in primary sex determination of the organism. Two candidate genes are the two testis-determining factors, ZFY and the master switch for differentiation of a testis SRY; they are putative transcription factors. It was shown that SRY and ZFY are transcribed in the hypothalamus and 
frontal and temporal cortex of adult men, and not in women. It may well be possible that they function as sex-specific cell-intrinsic signals that are needed for full differentiation of a male human brain, and that continuous expression throughout life may be required to maintain sex-specific structural or functional properties of differentiated male neurons.

\section{Sex Hormones}

During the development of the embryo in the womb, circulating hormones have a very important role in the sexual differentiation of the brain. Depending on the type of hormone and the level of hormonal activity during the embryonic stage of development can produce brains with male or female traits. The presence of androgens in early life produces a "male" brain. In contrast, lack of androgens causes feminization, and the female sex is developed by default in a passive mechanism. However, studies have shown that estrogen plays an active role in differentiation of the female brain [168-173] and that the sensitive period for estrogen related processes occurs at a later time than that of testosterone related processes [174]. It is known, at least, in rodent brains, estradiol and not testosterone is responsible for the masculinization of the brain. Testosterone, secreted from the testes in male fetuses is transported into the brain, where it is converted into estradiol by cytochrome $\mathrm{P} 450$ aromatase, locally expressed in different parts of the brain $[175,176]$. While female fetuses are not exposed to testosterone from their gonads, they are still exposed to estradiol from their mothers. To prevent masculinization of the female brain, large amounts of alpha-fetoprotein are present in the blood of female fetuses, which could bind estradiol and thus preventing it from entering into the brain [177].

In sexual differentiation of the human brain direct effects of testosterone seem to be of primary importance based upon evidence shown e.g. from subjects with mutations in the androgen receptor, estrogen receptor or in the aromatase gene [178]. In transsexuals, reversal of the sex difference in the central nucleus of the bed nucleus of the stria terminalis was observed. The size, type of innervation and neuron number agreed with their gender identity and not with their genetic sex [179, 180]. Various structural and functional brain differences related to sexual orientation have now also been reported [181-183]. Levels of circulating sex steroid hormones, during development and in adulthood, play a critical role in determining physiology and behavior in adulthood [184, 185]. Since the morphologic characteristics of neurons have been shown to influence the functional properties of the neurons [186-188], it is likely that these hormone-induced structural changes contribute significantly to the activation of neural circuits necessary for certain behaviors [189]. Recent findings suggest that manipulation of sex steroid hormone levels may induce dramatic macroscopic and microscopic structural changes in certain regions of the central nervous system, such as neurons of adult avian song system [190, 191], corpus callosum and anterior commissure [17, 192], bulbocavernosus spinal nucleus [193, 194], spinal motor neurons [195] rat Purkinje cell [196], sexual dimorphic nucleus of preoptic area of hypothalamus (SDN-POA) of hypothalamus [197], hippocampal pyramidal cells [198], bed nucleus of human stria terminalis [199], nigrostriatal dopamine neurons [200], rat arcuate nucleus [201-203], human median raphe nucleus [204], and substantia nigra [205]. Dorsal raphe nucleus (DRN) is the largest of all raphe nuclei in rat brain stem, and a part of serotonergic system [206]. Studies have also indentified many areas of the brain that are altered during development due to exposure to sex steroids, not only areas closely connected with reproduction, but also in the areas important for emotional responses such as amygdala and even other areas such as hippocampus and cerebellum [207, 208]. Substantial evidence indicates that sex hormones influence learning and memory processes [209], and interact with stress hormones to do so. In humans, the menstrual cycle significantly influences performance on both verbal and spatial tasks [210], and modulates the neural circuitry associated with arousal [4]. Menstrual cycle influences have even been detected on the degree of hemispheric asymmetry associated with various cognitive tasks [211]. Menstrual cycle influences also exist on brain responsiveness to addictive drugs such as cocaine [212] and amphetamines [213], factors that will probably help to explain sex differences in addictive processes [214]. In addition, sex hormones such as oestrogen can alter the excitability of hippocampal cells [215] strongly influence their dendritic structure [216] and augment NMDA (N-methyl-D-aspartate) receptor binding [217]. Intrahippocampal oestrogen infusions modulate memory processes [218]. Finally, sex differences exist in hippocampal long-term potentiation [219], a phenomenon that is widely viewed to be related to memory processes. Human behavior is also subject to the activational effects of androgens. Transsexuals treated with cross-sex hormones display sex reversals in their cognitive abilities, emotional tendencies, and libido [220, 221], and sex offenders are sometimes treated with antiandrogens to reduce their sex drive [222].

Several studies have suggested that sex steroid hormones might not be the whole answer to sexual differentiation and that sex chromosomes could influence sex specific development. Sex hormones are crucial for many sex differences, but, equally, cannot explain all observed sex differences. For example, a recent study reported several sex differences in cocaine-seeking behavior in rats and, in addition, found that these differences were unaffected by oestrus state [223]. Many of such sex differences described in the human brain arise during development by an interaction of sex hormones and the developing neurons, although direct genetic effects are probably also involved [181]. Factors influencing structural [43] and functional $[178,181]$ sex differences in the brain are genetic factors like mutations or polymorphisms in the sex hormone receptors, abnormal prenatal hormone levels and compounds such as anticonvulsants, Diethylstilbestrol (an estrogen-like compound) and environmental endocrine disrupters. When given during pregnancy they interact with the action of sex hormones on the fetal brain.

\section{Evolution}

The fundamental neurological substrate that forms the basis for complex cerebral asymmetries in Homo sapiens may have been established remarkably early in anthropoid evolution. In ancient times, both sexes had very defined role that helped ensure the survival of the species. Cave-men 
hunted while Cave-women gathered food near the home and cared for the children. Brain areas may have been sharpened to enable each sex to carry out their jobs. In evolutionary terms, developing superior navigation skills may have enabled men to become better suited to the role of hunter, while the development by females of a preference for landmarks may have enabled them to fulfill the task of gathering food closer to home [54]. The advantage of women regarding verbal skills also makes evolutionary sense. While men have the bodily strength to compete with other men, women use language to gain social advantage, such as by argumentation and persuasion [54]. Morning sickness, for example, which steers some women away from strong tastes and smells, may once have protected babies in utero from toxic items. Infidelity is a way for men to ensure genetic immortality [224]. Tendency toward cortical lateralization has been greatly elaborated in human evolution, such that at least $90 \%$ of extant humans are right-handed. Numerous data support an association of the left human hemisphere with time-sequencing, language skills, certain neurochemical asymmetries, and specific psychiatric disorders. The right hemisphere, on the other hand, is associated with holistic processing, visuospatial and musical abilities, emotional processing, and its own neurochemical and psychiatric properties. Significant sexual dimorphism in certain skills associated with cortical lateralization has been reported in humans. Females excel at language and fine motor skills, as well as emotional decoding and expression; males are relatively adept at composing music and exhibit visuospatial and mathematical skills [225]. Evolution can also produce adaptive sex differences in behavior and its neural substrate [226].

\section{Culture and Socialization}

Postnatal social factors are generally presumed to be involved in the development of sexual orientation [227, 228]. Females of all ages are better at recognizing emotion or relationships than are men. These sex-determined differences appear in infancy and the gap widens as people mature. When such differences appear early in development, it can be assumed that these differences are programmed into our brains-"hardwired" to use a computer analogy. Sex differences that grow larger throughout childhood however, are probably shaped by culture, lifestyle and training. Studies of brain plasticity have shown us that experience changes our brains structure.

At birth, the human brain is still preparing for full operation. The brain's task for the first 3 years is to establish and reinforce connections with other neurons. As a child develops, the synapses become more complex, like a tree with more branches and limbs growing. After age 3, the creation of synapses slows until about age 10 . Between birth and age 3 , the brain creates more synapses than it needs. The synapses that are used a lot become a permanent part of the brain. The synapses that are not used frequently are eliminated. This is where experience plays an important role in wiring a young child's brain. The child's experiences are the stimulation that sparks the activity between axons and dendrites and creates synapses. Clearly the social experience of a young baby is limited, but even then it is interacting, soaking up experience like a sponge. In an astonishingly short time it becomes proficient in a complicated, not entirely logical language. Even before an infant begins to talk, it understands sentences containing quite complex sequences. It is believed that nurturing one's brain can enhance what nature has provided. There is a lot of evidence that we build up our brain's representation of space by moving through it. Boys tend to get a lot more practice "moving through space" than girls do. This difference could possibly be erased if the girls are pushed out into the exploratory mode [97]. There is evidence that learning uses long-term potentiation (LTP) in the cerebral cortex as a way to strengthen synaptic connections between brain cells that are necessary to acquire and store new information [229]. Even with laboratory rats, it has been shown that those reared in a stimulating environment develop a much more intricate cerebral organization than those reared in nothing more than a bare cage. The more prominent sex differences were seen when the rearing environment was varied, with females showing less susceptibility to environmental influences in some neuronal populations [230].

\section{Susceptibility to Neurological Disorders}

Many CNS-related disorders show sex differences in their incidence and/or nature. These diseases include, but are not limited to, Alzheimer's disease (AD), post-traumatic stress disorder (PTSD) and other anxiety disorders, schizophrenia, stroke, multiple sclerosis, autism, addiction, fibromyalgia, attention deficit disorder, irritable bowel syndrome, Tourette's syndrome and eating disorders [231, 232]. Major depressive disorder, anxiety and eating disorders are much more prevalent in women, while schizophrenia, autism and attention deficit disorder are diagnosed more often in men [233]. The prefrontal cortex (PFC) performs important functions in the brain. It is rich in sex hormone receptors, and has among the highest concentration of oestrogen receptors in the human brain [234]. Sex differences in the neural substrate for working memory, a function, thought to depend on the prefrontal cortex (PFC), have been reported $[235,236]$. The PFC is also associated with sex differences in its response to stress. [237, 238] and might develop at different rates in males and females [239]. The PFC is thought to be involved in decision making. Tranel et al. [240] present evidence that right hemisphere PFC lesions impair performance on this decision-making task in men but not women, whereas left hemisphere lesions impair performance in women but not men. It was also reported in an earlier brain imaging study of PFC function in normal subjects performing the decision-making task [241]. Certain diseases that cause neuronal loss in the cerebral cortex may be more detrimental to women due to their lower number of cortical neurons compared to men $[242,243]$. The results of some studies suggest that Alzheimer's disease (AD) disproportionately affects women [244]. There are growing indications that the disease pathology, and the relationship between pathology and behavioral disturbance, differs significantly between the sexes. AD-related neurofibrillary pathology associated with abnormally phosphorylated tau protein differs in the hypothalamus of men and women: up to $90 \%$ of older men show this pathology, whereas it is found in only $8-10 \%$ of agematched women. An opposite sex difference occurs in the nucleus basalis of Meynert, the major source of cholinergic innervation to the neocortex. Here, the percentage of neurons 
containing pretangles with hyperphosphorylated tau protein is significantly higher in women than in men [245]. Other evidence indicates that the relationship of AD pathology to behavioral disruption also differs between the sexes. The presence of a single $\mathrm{APOE}^{*} \mathrm{E} 4$ allele (an allele of a gene associated with an increased risk of AD) has been linked with significantly greater hippocampal atrophy and memory disruption in women than in men [246]. As another example, symptoms of depression significantly increase the risk of developing $\mathrm{AD}$ in men, but not in women [247]. Finally, Barnes et al. [244] showed that the relationship between the presence of cortical neurofibrillary tangles and a clinical diagnosis of $\mathrm{AD}$ differed dramatically between men and women. Using regression models, they found that each unit increase in pathology was associated with an approximately 3 -fold increase in AD risk in men, but with a more than 20 fold increase in women.

Schizophrenia is another brain disease that differs in both incidence and nature between the sexes. Men and women differ on average in several clinical features of the disease, including its presentation, symptoms, age of onset, and the time course of the illness. Some patterns of brain morphology that are associated with the illness also differ between the sexes. Men with schizophrenia show significantly larger ventricles than do healthy men, whereas no such enlargement is seen in women with schizophrenia [248]. The ratio of the size of the amygdala to that of the orbitofrontal cortex, which is sexually dimorphic in healthy individuals, is increased in men with psychosis, but decreased in women with psychosis [249]. Results of studies from several laboratories [250] indicate that the normal patterns of hemispheric asymmetry seen in the brains of healthy individuals are reduced in schizophrenia, and that sex interacts with the changes in asymmetry. Sex differences even occur in the facial features of patients with schizophrenia: male patients display significantly less facial hemispheric asymmetry than do male controls, whereas female patients display marked facial asymmetries that are absent in female controls [251]. Significant interactive effects of sex and frontal lobe volume were found in regression analyses of the disorganization and suspicionhostility symptom scales. In men, higher frontal lobe volume was associated with milder severity of disorganization but was not correlated with severity of suspicion-hostility. In women, higher frontal lobe volume was associated with more severe disorganization as well as more severe suspicion-hostility. No associations were found between brain volume and severity of negative or Schneiderian symptoms. These findings suggest that aspects of the neuropathological basis for some symptoms of schizophrenia may be sexually dimorphic [252].

It has been proposed that neuropsychiatric illnesses, such as schizophrenia, with a typical adolescent onset may be mediated by excess elimination of synapses [253, 254]. The rapid rate of periadolescent pruning in males may underlie the early age of onset and increased illness severity in male schizophrenic patients [255, 256]. Previous studies in infants and older children find that white matter FA increases and ADC (apparent diffusion coefficient) decreases with age [257-259]. Gilmore et al. [260] observed a significant increase in FA in the genu and splenium of the corpus callosum, but not in other white matter tracts. This suggests that the white matter of the corpus callosum is undergoing significant maturation in the period after birth that may represent a window of vulnerability to perinatal insults that have been associated with neurodevelopmental disorders, including schizophrenia. Becker [261] has discovered clear sex differences in the levels of dopamine in several brain regions, as well as differences in the responsiveness of dopamine to stimulation by amphetamine and sex hormones. In humans, addiction differs between the sexes in important ways. Women, for example, are more sensitive than men to the reinforcing effects of psychostimulants (for example, amphetamine and cocaine), which may account for the more rapid progression from initial use to drug dependence in women compared with men [262].

Women and men tend to have different types of stressrelated psychological disorders. Women have greater rates of depression and some types of anxiety disorders than men, while men have greater rates of alcohol-use disorders than women [263]. Based on neuroendocrine and behavioral evidence stress responses may be characterized by 'fight-orflight' in men and 'tend-and-be friend' in women [264]. Under stressful situations, the 'fight-or-flight' response invokes resources that increase focus, alertness and fear, while inhibiting appetitive goals to cope with the threat or challenge $[185,265]$ In contrast, the female stress response primarily involves the limbic system including ventral striatum, putamen, insula and cingulate cortex. Both men and women's brain activation lasted beyond the stress task, but the lasting response in the female brain was stronger. The asymmetric prefrontal activity in males was associated with a physiological index of stress responses-salivary cortisol, whereas the female limbic activation showed a lower degree of correlations with cortisol [266]. Women are more likely than men to focus on negative emotional aspects of stressful circumstances [263]. The female intelligence processing is more centralized in the brains frontal lobes [106]. Therefore the frontal lobe injuries can be more detrimental to cognitive performance in women than men. Among brain injury patients, after damage to the left hemisphere, long term speech difficulties occur three times more often in males.

In a study it was found that for females, areas in both the left and right sides of the brain were active during eye-hand co-ordination experiments. That occurred for men only when they were planning their most complex task: This gives insight to why different types of head injuries are more disastrous to one sex or the other. For example, in women 84 percent of grey matter regions and 86 percent of white matter regions involved in intellectual performance were located in the frontal lobes, whereas the percentages of these regions in a man's frontal lobes are 45 percent and zero, respectively. Clinical data shows that frontal lobe damage in women is much more destructive than the same type of damage in men. Rehabilitation after brain injuries such as stroke may need to be tailored to the sex of the person. The research findings suggest that if someone has a stroke on one side of the brain, in one of the areas that differs between males and females, it may be important to take into account the sex of the patient. If the stroke is only on one side of the brain, a woman may have rehabilitation options that the man may have more trouble with because the woman may be able to perform tasks using the other side of her brain, which is used 
to being fired up. Men may have more trouble with rehabilitation, and may need to be checked more carefully before they resume everyday activities. Boys also fall prey to learning disabilities, for example, dyslexia and attention deficit hyperactivity disorder (ADHD) are more frequently seen in boys than girls. The symptoms displayed by girls and boys with ADHD differ, too. Girls with ADHD usually exhibit inattention, while affected boys are prone to lack of impulse control [97].

There is a clear sex difference in psychiatric disorders such as depression: the prevalence, incidence and morbidity risk is higher in females than in males, which may be due to both organizing and activating effects of sex hormones on the hypothalamo-pituitary-adrenal-axis. Fluctuations in sex hormone levels are considered to be involved in the susceptibility to depression, seen e.g. in the premenstrual, ante-and postpartum period, during the transition phase to the menopause and during oral contraceptives treatment. It was found that about $40 \%$ of the activated corticotropin releasing hormone $(\mathrm{CRH})$ neurons in the hypothalamic paraventricular nucleus in mood disorders expresses also the estrogen receptor (ER) [267]. Estrogen-responsive elements are found in the $\mathrm{CRH}$ gene promoter region, while estrogens stimulate CRH expression in animal studies. An androgenresponsive element in the $\mathrm{CRH}$ gene promoter region has also been identified, which initiates a suppressing effect on $\mathrm{CRH}$ expression [268]. Distinct liability for men and women to suffer from some psychiatric disorders responding to serotonergic agents may be related to differences in brain serotonin receptors.

Autoimmune diseases are more prevalent in women than in men. In multiple sclerosis (MS), a chronic inflammatory demyelinating disease of the central nervous system (CNS), there is a female-to-male preponderance approaching 2: 1 to 3: 1. The MS-associated HLA-DR2 allele is more frequent in women than in men with MS [269] and there is evidence that women develop MS at an earlier age than men [270]. Although MS is more common in women and may appear earlier, there is evidence that disease severity is worse in men. Male patients are somehow especially vulnerable to cognitive deficits [271]. Systemic lupus erythematosus (SLE) is nine times more common in women than in men, but men exhibit differences in clinical presentation, with an increased prevalence of SLE-associated renal disease, vascular thrombosis, pleuropericardial disease, peripheral neuropathy, and seizures as compared to women [272]. Hormonal shifts in pregnancy, menopause, and aging are associated with fluctuations in the course of autoimmune disease. Multiple sclerosis and rheumatoid arthritis, for example, improve during pregnancy, whereas lupus appears to worsen. Steroid receptors are found in immune cells and thus could provide a plausible pathway by which steroid hormones affect autoimmunity [273].

Sex differences in brain development may be related to the prevalence, course and treatment of several neuropsychiatric disorders, such as autism and attention deficit hyperactivity disorder [255, 256]. Autism and attention deficit show strong sexual dimorphism and are thought to originate from the dysfunction of cerebellum [207]. Males are at least four times more likely to develop autism, a highly heritable disorder, than females. Among relatives with a broader autistic phenotype, males predominate too. The threshold for phenotypic expression of many autistic characteristics is influenced by imprinted Xlinked gene(s) [274]. Clinical samples of attention deficit hyperactivity disorder have been dominated by males. Gender differences in ADHD may be attributable to gender differences in dopamine receptor density. The rise of male, but not female, striatal dopamine receptors parallels the early developmental appearance of motor symptoms of ADHD. Transient lateralized $\mathrm{D}_{2}$ dopamine receptors in male striatum may increase vulnerability to ADHD [139].

\section{GENDER DIFFERENCES AND LEARNING}

Research on the differences between male and female brain structure and function has huge implications for educational theory. Male and female brains are wired differently and that is why they learn, feel and react so differently. Studies have shown that girls tend to use the areas of the brain devoted to verbal and emotional functioning, while boys generally use the areas of the brain geared toward spatial and mechanical tasks [275]. The male brain needs to recharge and reorient by entering what brain scientists call a rest state. Boys may naturally drift off or "space out" during a lesson. However, they are able to stay engaged in visual or hands-on learning that involves symbols, objects, diagrams and pictures but zone out when too many words are used [276]. Active learning strengthens neuronal pathways, builds new ones and improves memory skills, reasoning and visualization efficiency.

\section{CONCLUSION}

The male and the female brains show anatomical, functional and biochemical differences in all stages of life. These differences begin early during development due to a combination of genetic and hormonal events and continue throughout the lifespan of an individual, and are involved in many functions in heath as well as in diseases. Mental and emotional health is extremely important to healthy aging. Sex differences need to be considered in studying brain structure and function. It may raise the possibility of early diagnosis and precise treatment and management for neurological diseases, and may help physicians and scientists to discover new diagnostic tools to explore the brain differences. Understanding the development of normal brain and differences between the sexes is important for the interpretation of clinical imaging studies.

\section{REFERENCES}

[1] Parent A, Carpenter MB. Carpenter's human neuroanatomy. Baltimore: Williams \& Wilkins 1995.

[2] Cosgrove KP, Mazure CM, Staley JK. Evolving knowledge of sex differences in brain structure, function, and chemistry. Biol Psychiatry 2007; 62: 847-55.

[3] Ho KC, Roessmann U, Straumfjord JV, Monroe G. Analysis of brain weight. II. Adult brain weight in relation to body height, weight, and surface area. Arch Pathol Lab Med 1980; 104(12): 640-5.

[4] Goldstein JM, Seidman LJ, Horton NJ, et al. Normal sexual dimorphism of the adult human brain assessed by In vivo Magnetic Resonance Imaging. Cereb Cortex 2001; 11(6): 490-7.

[5] Allen JS, Damasio H, Grabowski TJ, Bruss J, Zhang W. Sexual dimorphism and asymmetries in the gray-white composition of the human cerebrum. NeuroImage 2003; 18: 880-94. 
[6] Gur RC, Turetsky BI, Matsui M, et al. Sex differences in brain gray and white matter in healthy young adults: correlations with cognitive performance. J Neurosci 1999; 19(10): 4065-72.

[7] Kaufmann CWM, Putz B, Auer D. Gender differences in brain morphology: Voxel Based Morphometry in 102 healthy young women and men. Proc Intl Mag Reson Med 2001; 9.

[8] Leonard CM, Towler S, Welcome S, et al. Size matters: cerebral volume influences sex differences in neuroanatomy. Cereb Cortex 2008; 18(12): 2920-31.

[9] Marner L, Nyengaard JR, Tang Y, Pakkenberg B. Marked loss of myelinated nerve fibers in the human brain with age. J Comp Neurol 2003; 462(2): 144-52.

[10] Witelson SF, Glezer II, Kigar DL. Women have greater density of neurons in posterior temporal cortex. J Neurosci 1995; 15: 341828.

[11] Pakkenberg B, Gundersen HJ. Neocortical neuron number in humans: Effect of sex and age. J Comp Neurol 1997; 384: 312-20.

[12] Hsu J, Leemans A, Bai C, et al. Gender differences and age-related white matter changes of the human brain: A diffusion tensor imaging study. Neuroimage 2008; 39(2): 566-77.

[13] LeVay S. A difference in hypothalamic structure between homosexual and heterosexual men. Science 1991; 253: 1034-7.

[14] Raisman G, Field PM. Sexual dimorphism in the preoptic area of the rat. Science 1971; 173: 731-3.

[15] Allen LS, Hines M, Shryne JE Gorski RA. Two sexually dimorphic cell groups in the human brain. J Neurosci 1989; 9: 497-506.

[16] Fernandez-Guasti A, Kruijver FPM, Fodor M, Swaab DF. Sex differences in the distribution of androgen receptors in the human hypothalamus. J Comp Neurol 2000; 425: 422-35.

[17] Allen LS, Gorski RA. Sexual dimorphism of the anterior commissure and massa intermedia of the human brain. J Comp Neurol 1991; 312: 97-104.

[18] Raz N, Dixon F, Williamson A, Head D. Age and sex differences in the cerebellum and the ventral pons: a prospective MR study of healthy adults. AJNR Am J Neuroradiol 2001; 22(6): 1161-7.

[19] Sowell ER, Peterson BG, Kan E, et al. Sex differences in cortical thickness mapped in 176 healthy individuals between 7 and 87 years of age. Cereb Cortex 2007; 17: 1550-60.

[20] Rabinowicz T, Dean DE, Petetot JM, de Courten-Myers GM. Gender differences in the human cerebral cortex: more neurons in males; more processes in females. J Child Neurol 1999; 14: 98-107.

[21] Harasty J, Double KL, Halliday GM, Kril JJ, McRitchie DA. Language-associated cortical regions are proportionally larger in the female brain. Arch Neurol 1997; 54: 17-6.

[22] Amunts K, Schleicher A, Bürgel U, Mohlberg H, Uylings HBM, Zilles K. Broca's region revisited: cytoarchitecture and intersubject variability. J Comp Neurol 1999; 412: 319-41.

[23] Amunts k, Armstrong E, Malikovic A, et al. Gender-specific leftright asymmetries in human visual cortex. J Neurosci 2007; 27: 1356-64.

[24] Haug H. Brain sizes, surfaces, and neuronal sizes of the cortex cerebri: a stereological investigation of man and his variability and a comparison with some mammals (primates, whales, marsupials, insectivores, and one elephant). Am J Anat 1987; 180: 126-42.

[25] Jacobs B, Batal HA, Lynch B, Ojemann G, Ojemann LM, Scheibel AB. Quantitative dendritic and spine analyses of speech cortices: a case study. Brain Lang 2003; 44: 239-53.

[26] Luders E, Narr KL, Zaidel E, Thompson PM, Jancke L, Toga AW. Parasagittal asymmetries of the corpus callosum. Cereb Cortex 2006; 16(3): 346-54.

[27] Alonso-Nanclares L, Gonzalez-Soriano J, Rodriguez JR, DeFelipe J. Gender differences in human cortical synaptic density. Proc Natl Acad Sci USA 2008; 105(38): 14615-9.

[28] Gur RC, Gunning-Dixon FM, Turetsky BI, Bilker WB, Gur RE. Brain region and sex differences in age association with brain volume: a quantitative MRI study of healthy young adults. Am J Geriatr Psychiatry 2002; 10(1): 72-80.

[29] Bell AH. Butterflies be gone: a hands-on approach to sweat-proof public speaking call number [eBook]. Chicago, Ill: McGraw-Hill 2008.

[30] Bishop KM, Wahlsten D. Sex differences in the human corpus callosum: myth or reality? Neurosci Biobehav Rev 1997; 21(5): 58601.

[31] Lee B, Sohn J, Choi M, et al. A volumetric study of the corpus callosum in 20s and 40s Korean people. Brain Struct Funct 2009; 213(4-5): 463-7.
[32] Luders E, Narr KL, Thompson PM, et al. Gender effects on cortical thickness and the influence of scaling. Hum. Brain Mapp 2006; 27(4): 314-24

[33] Luders E, Rex DE, Narr KL, et al. Relationships between sulcal asymmetries and corpus callosum size: gender and handedness effects. Cereb Cortex 2003; 13: 1084-93.

[34] Frederikse AL, Aylward E, Barta P, Pearlson G. Sex Differences in the inferior parietal lobule. Cereb Cortex 1999; 9(8): 896-901.

[35] Sabbatini RME. Are there differences between the brains of males and females? Brain Mind Mag October/December 2000.

[36] Wood JL, Heitmiller D, Andreasen N C, Nopoulos P. Morphology of the ventral frontal cortex: relationship to femininity and social cognition. Cereb Cortex 2008; 18(3): 534-40.

[37] Juraska JM. Sex differences in 'cognitive' regions of the rat brain. Psychoneuroendocrinology 1991; 16: 105-9.

[38] Madeira MD, Lieberman AR. Sexual dimorphism in the mammalian limbic system. Prog Neurobiol 1995; 45: 275-333.

[39] Cahill L, Uncapher M, Kilpatrick L, Alkire MT, Turner J. Sexrelated hemispheric lateralization of amygdala function in emotionally influenced memory: an fMRI investigation. Learn Mem 2004; 11: 261-6.

[40] Hamann S. Sex differences in the responses of the human amygdala. Neuroscientist 2005; 11:288-93.

[41] Mechelli A, Friston KJ, Frackowiak RS, Price CJ. Structural covariance in the human cortex. J. Neurosci 2005; 25: 8303-10.

[42] Sarah D, Pol H, Hilleke E, et al. Anatomical MRI of the developing human brain: What have we learned? J Am Acad Child Adolesc Psychiatry 2001; 40(9): 1012-20.

[43] Swaab DF, Fliers E. A sexually dimorphic nucleus in the human brain. Science 1985; 228: 1112-14.

[44] Allen LS, Gorski RA. Sex difference in the bed nucleus of the stria terminalis of the human brain. J Comp Neurol 1990; 302: 697-706.

[45] Schlaepfer TE, Harris GJ, Tien AY, Peng L, Lee S, Pearlson GD. Structural differences in the cerebral cortex of healthy female and male subjects: a magnetic resonance imaging study. Psychiatry Res 1995; 61: 129-35.

[46] Giedd JN, Vaituzis AC, Hamburger SD, et al. Quantitative MRI of the temporal lobe, amygdala, and hippocampus in normal human development: ages 4-18 years. J Comp Neurol 1996; 366: 223-30.

[47] McGaugh JL. The amygdala modulates the consolidation of memories of emotionally arousing experiences. Ann Rev Neurosci 2004; 27: 1-28.

[48] Cahill L. The amygdala: a functional Analysis. In: Aggleton J, Ed. London: Oxford Univ Press 2000; pp. 425-44.

[49] Cahill L, Haier RJ, White NS, et al. Sex-related difference in amygdala activity during emotionally influenced memory storage. Neurobiol Learn Mem 2001; 75: 1-9.

[50] Canli T, Desmond J, Zhao Z, Gabrieli JDE. Sex differences in the neural basis of emotional memories. Proc Natl Acad Sci USA 2002; 99: 10789-94.

[51] Cahill L, Uncapher M, Kilpatrick L, Alkire MT, Turner J. Sexrelated hemispheric lateralization of amygdala function in emotionally influenced memory: an fMRI investigation. Learn Mem 2004; 11: 26-6.

[52] Lalumiere RT, McGaugh JL. Memory enhancement induced by post-training intrabasolateral amygdala infusions of $\beta$-adrenergic or muscarinic agonists requires activation of dopamine receptors: involvement of right, but not left, basolateral amygdala. Learn Mem 2005; 12: 527-32.

[53] Kilpatrick L, Cahill L. Amygdala modulation of parahippocampal and frontal regions during emotionally influenced memory storage. NeuroImage 2003; 20(4): 2091-9.

[54] Geary DC. Chapter 8: sex differences in brain and cognition. In: Male, female: the evolution of human sex differences. Washington D.C.: American Psychological Association Books 1998; p. 153

[55] Canli T, Zhao Z, Brewer J, Gabrieli JD, Canhill L. Event-related activation in the human amygdala associates with later memory for individual emotional experience. J Neurosci 2000; 20(19): RC99.

[56] Harasty J, Double KL, Halliday GM, Kril JJ, McRitchie DA. Language-associated cortical regions are proportionally larger in the female brain. Arch Neurol 1997; 54 (2) 171-6.

[57] Shaywitz BA, Shaywitz SE, Pugh KR, et al. Sex differences in the functional organization of the brain for language. Nature 1995; 373(6515): 607-9. 
[58] Burmann DD, Bitan T, Booth JR. Sex differences in neural processing of language among children. Neuropsychologia 2008; 46(5): 1349-62.

[59] Kansaku K, Yamaura A, Kitazawa S. Sex differences in lateralization revealed in posterior language areas. Cereb Cortex 2000; 10: 866-82.

[60] Schlösser R, Hutchinson M, Joseffer S, et al. Functional magnetic resonance imaging of human brain activity in a verbal fluency task. J Neurol Neurosurg Psychiatry 1998; 64: 492-8.

[61] Hoag H. Sex on the brain. New Sci 2008; 199: 28-31.

[62] Kolata G. Men and women use brain differently, study discovers. The New York Times. February 16,1995.

[63] Piefke M, Weiss P, Markowitsch H, Fink G. Gender differences in the functional neuroanatomy of emotional episodic autobiographical memory. Hum Brain Mapp 2005; 24: 313-24.

[64] Grabowski TJ, Damasio H, Eichhorn GR, Tranel D. Effects of gender on blood flow correlates of naming concrete entities. NeuroImage 2003; 20: 940-54.

[65] Konrad C, Engelien A, Schoning S, et al. The functional anatomy of semantic retrieval is influenced by gender, menstrual cycle, and sex hormones. J Neural Transm 2008; 115(9): 1327-37.

[66] Clements AM, Rimrodt SL, Abel JR, et al. Sex differences in cerebral laterality of language and visuospatial processing. Brain Lang 2006; 98(2): 150-8.

[67] Halari R, Sharma T, Hines M, Andrew C, Simmons A, Kumari V. Comparable fMRI activity with differential behavioural performance on mental rotation and overt verbal fluency tasks in healthy men and women. Exp Brain Res 2006; 169(1): 1-14.

[68] Gur RC, Alsop D, Glahn D, et al. An fMRI study of sex differences in regional activation to a verbal and a spatial task. Brain Lang 2000; 74(2): 157-70

[69] Gilmore JH, Zhai G, Wilber K, Smith JK, Lin W, Gerig G. 3 Tesla magnetic resonance imaging of the brain in newborns. Psychiatry Res 2004; 132(1): 81-5.

[70] Reiss AL, Abrams MT, Singer HS, Ross JL, Denckla MB. Brain development, gender and IQ in children: a volumetric study. Brain 1996; 119: 1763-74

[71] Jacklin CN, Martin LJ. Effects of gender on behavior and development. In: Levine MD, Carey WB, Crocker AC, Eds. Developmental-behavioral pediatrics. $3^{\text {rd }}$ ed. Philadelphia, PA: W.B. Saunders 1999; pp. 100-6.

[72] Hampson E, Kimura D. Sex differences and hormonal influences on cognitive function in humans. In: Becker JB, Breedlove JB, Crews D, Eds. Behavioral endocrinology. Cambridge, MA: MIT Press 1992; pp. 357-97.

[73] Kimura D. Sex, sexual orientation and sex hormones influence human cognitive function. Curr Opin Neurobiol 1996; 6: 259-63.

[74] Janowsky JS, Chaves B, Zamboni BD, Orwoll E. The cognitive neuropsychology of sex hormones in men and women. Dev Neuropsychol 1998; 14: 421-40.

[75] Gur RC, Mozley LH, Mozley PD, et al. Sex differences in regional cerebral glucose metabolism during a resting state. Science 1995; 267: 528-31

[76] Kimura, D. Sex differences in the brain. Sci Am 1992; 67: 118-25.

[77] Ray WJ, Newcombe N, Semon J, Cole PM. Spatial abilities, sex differences and EEG functioning. Neuropsychologia 1981; 19: 71922.

[78] Halpern DF. Sex differences and cognitive abilities. $3^{\text {rd }}$ ed. Mahwah, NJ: Lawrence Erlbaum Associates Inc 2000.

[79] Crick NR, Grotpeter JK. Relational aggression, gender and socialpsychological adjustment. Child Dev 1995; 66: 710-22.

[80] Linn MC, Petersen AC. Emergence and characterization of sex differences in spatial ability: a meta-analysis. Child Dev1985; 56: 1479-98.

[81] Baron-Cohen S. The essential difference: men, women and the extreme male brain. Verlag: Allen Lane Science 2003.

[82] Wilson EO. Sociobiology. Cambridge, MA: Harvard University Press 1992.

[83] Hoffman ML. Sex differences in empathy and related behaviors. Psychol Bull 1977; 84: 712-22.

[84] Ahlgren A, Johnson DW. Sex differences in cooperative and competitive attitudes from the 2 nd to the 12 th grades. Dev Psychol 1979; 15: 45-9.

[85] Kimura D. Sex and cognition. Cambridge, MA: MIT Press 1999.
[86] Phillips MD, Lowe MJ, Lurito JT, Dzemidzic M, Mathews VP. Temporal lobe activation demonstrates sex-based differences during passive listening. Radiology 2001; 220(1): 202-7.

[87] Kansaku K, Kitazawa S. Imaging studies on sex differences in the lateralization of language. Neurosci Res 2001; 41(4): 333-7.

[88] Berk LE. Child development. $4^{\text {th }}$ ed. Boston, MA: Allyn and Bacon 1997.

[89] de Courten-Myers GM. The human cerebral cortex: gender differences in structure and function. J Neuropathol Exp Neurol 1999; 58(3): 217-26.

[90] Wolke D. Psychological development of prematurely born children. Arch Dis Child 1998; 78: 567-70.

[91] Arnold PA. Genetically triggered sexual differentiation of brain and behaviour. Horm Behav 1996; 30; 495-505.

[92] Forest MG, De Peretti E, Bertrand J. Hypothalamic-pituitarygonad relationships in humans from birth to puberty. Endocrinology 1976; 5: 551-65.

[93] McEwan BS. Steroid hormones: effect on brain development and function. Horm Res 1992; 37(Suppl 3): 1-10.

[94] Kirn J, Lombraso PJ. Development of the cerebral cortex: XI Sexual dimorphism in the brain. J Am Acad Child Adolesc Psychiatry 1998; 37: 1228-30.

[95] Brothwood M, Wolke D, Gamsu H, Benson J, Cooper D. Prognosis of the very low birth weight baby in relation to gender. Arch Dis Child 1986; 61: 559-64.

[96] Hindmarsh GJ, O’Callaghan MJ, Mohay HA, Rogers YM. Gender differences in cognitive abilities at 2 years in ELBW infants. Early Hum Dev 2000; 60(2): 115-22.

[97] Denckla MB, Rudel RG, Chapman C, Krieger J. Motor proficiency in dyslexic children with and without attentional disorders. Arch Neurol 1985; 42(3): 228-31.

[98] Gron G, Wunderlich AP, Spitzer M, Tomczak R, Riepe MW. Brain activation during human navigation: gender-different neura networks as substrate of performance. Nat Neurosci 2000; 3(4): 404-8.

[99] Gur RE, Skolnick BE, Gur RC, et al. Brain function in psychiatric disorders. I. Regional cerebral blood flow in medicated schizophrenics. Arch Gen Psychiatry 1983; 40(11): 1250-4.

[100] Gorbet DJ, Sergio LE. Preliminary sex differences in human cortical BOLD fMRI activity during the preparation of increasingly complex visually guided movements. Eur J Neurosci 2007; 25 (4): 1228-39

[101] Weis S, Hausmann M, Stoffers B, Vohn R, Kellermann T, Sturm W. Estradiol modulates functional brain organization during the menstrual cycle: an analysis of interhemispheric inhibition. J Neurosci 2008; 28 (50): 13401-10.

[102] Kitazawa S, Kansaku K. Sex difference in language lateralization may be task-dependent. Brain 2005; 128: E30.

[103] Hill H, Ott F, Herbert C, Weisbrod M. Response execution in lexical decision tasks obscures sex-specific lateralization effects in language processing: evidence from event-related potential measures during word reading. Cereb Cortex 2006; 16(7): 978-89.

[104] Piccardi L, Iaria G, Ricci M, Bianchini F, Zompanti L, Guariglia C. Walking in the Corsi test: which type of memory do you need? Neurosci Lett 2008; 432(2): 127-31.

[105] Chai XJ, Jacobs LF. Sex differences in directional cue use in a virtual landscape. Behav Neurosci 2009; 123(2): 276-83.

[106] Haier RJ, Jung RE, Yeo RA, Head K, Alkire MT. The neuroanatomy of general intelligence: sex matters. Neuroimage 2005; 25(1): 320-7.

[107] Lynn R. Sex differences in intelligence and brain size: a developmental theory. Intelligence 1999; 27(1): 1-12.

[108] Reiss Al, Abrams MT, Singer HS, Ross JL, Denckla MB. Brain development, gender and IQ in children: a volumetric imaging study. Neurology 2000; 54: 2224-9.

[109] Bechara A, Damasio AR, Damasio H, Anderson SW. Insensitivity to future consequences following damage to human prefrontal cortex. Cognition 1994; 50: 7-15.

[110] Bechara A, Damasio H, Tranel D, Damasio AR. Deciding advantageously before knowing the advantageous strategy. Science 1997; 275: 1293-5.

[111] Fuster JM. The prefrontal cortex: anatomy, physiology, and neuropsychology of the frontal lobe. $3^{\text {rd }}$ ed. Philadelphia, PA: Lippincott-Raven 1997.

[112] Damasio AR. The somatic marker hypothesis and the possible functions of the prefrontal cortex. In: Roberts AC, Robbins TW, 
Weiskrantz L, Eds. The Prefrontal cortex: executive and cognitive functions. New York, NY: Oxford University Press 1998; pp. 3650 .

[113] Pandya DN, Yeterian EH. Comparison of prefrontal architecture and connections. In: Roberts AC, Robbins TW, Weiskrantz L, Eds. The prefrontal cortex. Oxford: Oxford University Press 1998. pp. 51-66.

[114] Smith EE, Jonides J. Storage and executive processes in the frontal lobes. Science 1999; 283: 1657-61.

[115] Grachev ID, Apkarian AV. Anxiety in healthy humans is associated with orbital frontal chemistry. Mol Psychiatry 2000; 5: 482-8.

[116] Miller BL. A review of chemical issues in 1H NMR spectroscopy: $\mathrm{N}$-acetyl-L-aspartate, creatine, and choline. NMR Biomed 1991; 4: 47-52.

[117] Castillo M, Kwock L, Scatliff J, Mukherji S. Proton MR spectroscopy in neoplastic and non-neoplastic brain disorders. Magn Reson Imaging Clin N Am 1998; 6: 1-20.

[118] Gur RC, Gur RE, Obrist WD, et al. Sex and handedness differences in cerebral blood flow during rest and cognitive activity. Science (New York, N.Y.) 1982; 217(4560): 659-61.

[119] Devous MD, Stokely EM, Chehabi HH, Bont FJ. Normal distribution of regional cerebral blood flow measured by dynamic single-photon emission tomography. J Cereb Blood Flow Metab 1986; 6: 95-104.

[120] Baxter LR, Phelps ME, Mazziotta JC, et al. Local cerebral glucose metabolic rates in obsessive-compulsive disorder. Arch Gen Psychiatry 1987; 44: 1008-14

[121] Rodriguez G, Warkentin S, Risberg J, Rosadini G. Sex differences in regional cerebral blood flow. J Cereb Blood Flow Metab 1988; 8: 783-9.

[122] Yoshii F, Barker WW, Chang JY, et al. Sensitivity of cerebral glucose metabolism to age, gender, brain volume, brain atrophy, and cerebrovascular risk factors. J Cereb Blood Flow Metab 1988; 8: 654-61.

[123] Baxter LR Jr, Mazziotta JC, Phelps ME, et al. Cerebral glucose metabolic rates in normal human females vs normal males. Psychiatry Res 1987; 2 I: 24.

[124] Ramsay SC, Murphy K, Shea SA, et al. Changes in global cerebral blood flow in humans: effect on regional cerebral blood flow during a neural activation task. J Physiol I993; 471: 521-34.

[125] Ragland JD, Coleman AR, Gur RC, Glanhn DC, Gur RE. Sex differences in brain-behavior relationships between verbal episodic memory and resting regional cerebral blood flow. Neuropsychologia 2000; 38(4): 451-61.

[126] Gur RE, Gur RC. Gender differences in regional cerebral blood flow. Schizophr Bull 1990; 16(2): 247-54.

[127] Gottfries CG, Roos BE, Winblad B. Determination of 5hydroxytryptamine, 5-hydroxyindoleacetic acid and homovanillic acid in brain tissue from an autopsy material. Acta Psychiatr Scand 1974; 50: 496-507.

[128] Cordero ME, Rodriguez A, Torres R, Valenzuela CY. Human raphe magnus nucleus: a morphometric Golgi-Cox study with emphasis on sex differences. Brain Res Dev Brain Res 2001; 131: 85-92.

[129] Nishizawa S, Benkelfat C, Young SN, et al. Differences between males and females in rates of serotonin synthesis in human brain. Proc Natl Acad Sci USA 1997; 94: 5308-13.

[130] Jonsson EG, Norton N, Gustavsson JP, Oreland L, Owen MJ, Sedvall GC. A promoter polymorphism in the monoamine oxidase A gene and its relationships to monoamine metabolite concentrations in CSF of healthy volunteers. J Psychiatr Res 2000; 34: 23944.

[131] Kornstein SG, Schatzberg AF, Thase ME, et al. Gender differences in chronic major and double depression. J Affect Disord 2000; 60: $1-11$.

[132] Williams RB, Marchuk DA, Gadde KM, Barefoot JC, Grichnik K, Helms MJ. Serotonin-related gene polymorphisms and central nervous system serotonin function. Neuropsychopharmacology 2003; 28: 533-41.

[133] Brummett BH, Boyle SH, Kuhn CM, et al. Associations among central nervous system serotonergic function and neuroticism are moderated by gender. Biol Psychol 2008; 78(2): 200-3.

[134] Biver F, Lotstra F, Monclus M, et al. Sex difference in 5HT2 receptor in the living human brain. Neurosci Lett 1996; 204: (1-2) $25-8$.
[135] Jovanovic H, Lundberg J, Karlsson P, et al. Sex differences in the serotonin $1 \mathrm{~A}$ receptor and serotonin transporter binding in the human brain measured by PET. Neuroimage 2008; 39(3); 1408-19.

[136] Turner BB, Weaver DA. Sexual dimorphism of glucocorticoid binding in rat brain. Brain Res 1985; 343: 16-23.

[137] Morissette M, Di Paolo T. Sex and estrous cycle variations of rat striatal dopamine uptake sites. Neuroendocrinology 1985; 58: 1622

[138] Becker JB. Gender differences in dopaminergic function in striatum and nucleus accumbens. Pharmacol Biochem Behav 1999; 64: 803-12.

[139] Andersen SL, Teicher MH. Sex differences in dopamine receptors and their relevance to ADHD. Neurosci Biobehav Rev 2000; 24(1): 137-41.

[140] Carroll ME, Lynch WJ, Roth ME, Morgan AD, Cosgrove KP. Sex and estrogen influence drug abuse. Trends Pharmacol Sci 2004; 25: 273-9.

[141] Laakso A, Vilkman H, Bergman J, et al. Sex differences in striatal presynaptic dopamine synthesis capacity in healthy subjects. Biol Psychiatry 2002; 52: 759-63.

[142] Pohjalainen T, Rinne JO, Nogren K, Syvalahti E, Hietala J. Sex differences in the striatal dopamine $\mathrm{D}_{2}$ receptor binding characteristics in vivo. Am J Psychiatry 1998; 155: 768-73.

[143] Munro CA, McCaul ME, Wong DF, et al. Sex differences in striatal dopamine release in healthy adults. Biol Psychiatry 2006; 59: $966-74$

[144] Mozley LH, Gur RC, Mozley PD, Gur RE. Striatal dopamine transporters and cognitive functioning in healthy men and women. Am J Psychiatry 2001; 158: 1492-9.

[145] Craft R M. Sex differences in opioid analgesia: 'from mouse to man'. Clin J Pain 2003; 19: 175-86.

[146] Robinson DS, Sourkes TL, Nies A, et al. Monoamine metabolism in human brain. Arch Gen Psychiatry 1977; 34: 89-92.

[147] Zhang J, Cai W, Zhou D, Su B. Distribution and differences of estrogen receptor beta immunoreactivity in the brain of adult male and female rats. Brain Res 2002; 935(1-2): 73-80.

[148] Barbarino A, De Marinis L, Mancini A, et al. Sex-related naloxone influence on growth hormone-releasing hormone-induced growth hormone secretion in normal subjects. Metabolism 1987; 36: 105-9.

[149] Zubieta J, Dannals RF, Frost JJ. Gender and age influences on human brain mu-opioid receptor binding measured by PET. Am J Psychiatry 1999; 156: 842-8.

[150] Gear RW, Miaskowski C, Gordon NC, Paul SM, Heller PH, Levine JD. Kappa-opioids produce significantly greater analgesia in women than in men. Nat Med 1996; 2: 1248-50.

[151] Harrison PJ, Tunbridge EM. Catechol-O-Methyltransferase (COMT): a gene contributing to sex differences in brain function, and to sexual dimorphism in the predisposition to psychiatric disorders. Neuropsychopharmacology 2008; 33: 3037-45.

[152] Karayiorgou M, Altemus M, Galke BL, et al. Genotype determining low catechol-O-methyltransferase activity as a risk factor for obsessive-compulsive disorder. Proc Natl Acad Sci USA 1997; 94: 4572-5.

[153] Chen JS, Lipska BK, Halim N, et al. Functional analysis of genetic variation in catechol-O-methyltransferase (COMT): effects on mRNA, protein, and enzyme activity in postmortem human brain Am J Hum Genet 2004; 75: 807-21.

[154] Achiron R, Lipitz S, Achiron A. Sex-related differences in the development of the human fetal corpus callosum: in uteroultrasonographic study. Prenat Diagn 2001; 21(2): 116-20.

[155] Caviness VS Jr, Kennedy DN, Richelme C, Rademacher J, Filipek PA. The human brain age 7-11 years: a volumetric analysis based on magnetic resonance images. Cereb Cortex 1996; 6: 726-36.

[156] De Bellis MD, Keshavan MS, Beers SR, et al. Sex differences in brain maturation during childhood and adolescence. Cereb Cortex 2001; 11(6): 552-7.

[157] Cowell PE, Turetsky BI, Gur RC, Grossman RI, Shtasel DL, Gur RE. Sex differences in aging of the human frontal and temporal lobes. J Neurosci 1994; 14: 4748-55.

[158] Yates MA, Markham JA, Anderson SE, Morris JR, Juraska JM. Regional variability in age-related loss of neurons from the primary visual cortex and medial prefrontal cortex of male and female rats. Brain Res 2008; 1218: 1-12.

[159] Gur RC, Mozley PD, Resnick SM, et al. Gender differences in age effect on brain atrophy measured by magnetic resonance imaging. Proc Natl Acad Sci USA 1991; 88(7): 2845-9. 
[160] Bocklandt S, Vilain E. Sex differences in brain and behavior: Hormones vs genes. Adv Genet 2007; 59: 245-66.

[161] Davies W, Wilkinson LS. It is not all hormones: alternative explanations for sexual differentiation of the brain. Brain Res 2006; 1126: $36-45$

[162] Arnold AP. Sex chromosomes and brain gender. Nat Rev Neurosci 2004; 5: 701-8.

[163] De Vries GJ, Rissman EF, Simerly RB, et al. A model system for study of sex chromosome effects on sexually dimorphic neural and behavioral traits. J Neurosci 2002; 22(20): 9005-14.

[164] Dewing P, Shi T, Horvath S, Vilain E. Sexually dimorphic gene expression in mouse. Mol Brain Res 2003; 118(1-2): 82-90.

[165] Kolbinger W, Trepel M, Beyer C, Pilgrim C, Reisert I. The influence of genetic sex on sexual differentiation of diencephalic dopaminergic neurons in vitro and in vivo. Brain Res 1991; 544(2): 349-52.

[166] Smith-Bouvier DL, Divekar AA, Sasidhar M, et al. A role for sex chromosome complement in the female bias in autoimmune disease. J Exp Med 2008; 205(5): 1099-108.

[167] Pilgrim C, Reisert I. Differences between male and female brains: developmental mechanisms and implications. Horm Metab Res 1992; 24: 353-9.

[168] Dohle KD, Hancke JL, Srivastava SS, Hofmann C, Shryne JE, Gorski RA. Participation of estrogens in female sexual differentiation of the brain: neuroanatomical, neuroendocrine and behavioral evidence. In: De Vries GJ, De Bruin JPC, Uylings HBM, Corner MA, Eds. Progress in Brain Research. Amsterdam: Elsevier Science Publishers 1984b; vol. 61: pp. 99-117.

[169] Dohler K. The pre-and postnatal influence of hormones and neurotransmitters on sexual differentiation of the mammalian hypothalamus. Int Rev Cytol 1991; 131: 1-57.

[170] Gerall A, Dunlap J, Hendricks S. Effects of ovarian secretions on female behavioral potentiality in the rat. J Comp Physiol Psychol 1973; 82: 449-65.

[171] Stewart J, Cygan D. Ovarian hormones act early in development to feminize open field behavior in the rat. Horm Behav 1980; 14: 2032.

[172] Toran-Allerand A. Sex steroids and the development of the newborn mouse hypothalamus and preoptic area in vitro: implication for sexual differentiation. Brain Res 1976; 106: 407-12.

[173] Toran-Allerand D. Organotypic culture of the developing cerebral cortex and hypothalamus: relevance to sexual differentiation. In: Tallal P, McEwen B, Eds. Psychoneuroendocrinology. New York: Pergamon Press 1992; vol. 16: pp. 7-24.

[174] Fitch RH, Denenberg VH. A role for ovarian hormones in sexual differentiation of the brain. Behav Brain Sci 1998; 21: 311-52.

[175] Lephart ED. A review of brain aromatase cytochrome P450. Brain Res Brain Res Rev 1996; 22(1): 1-26.

[176] Harada N. Estrogen synthetase (P-450. aromatase) as a regulatory factor concerning sexual differentiation of brain and sexual behavior--physiological functions and regulation of gene expression of aromatase. Seikagaku 1993; 65(2): 67-85.

[177] Bakker J, De Mees C, Douhard Q, et al. Alpha-fetoprotein protects the developing female mouse brain from masculinization and defeminization by estrogens. Nat Neurosci 2006; 9(2): 220-6.

[178] Swaab DF. Sexual differentiation of the human brain: Relevance for gender identity, transsexualism and sexual orientation. Gynecol Endocrinol 2004a; 19: 301-12.

[179] Zhou JN, Hofman MA, Gooren LJ, Swaab DF. A sex difference in the human brain and its relation to transsexuality. Nature 1995; 378: 68-70.

[180] Kruijver FP, Zhou JN, Pool CW, Hofman MA, Gooren LJ, Swaab DF. Male-to-female transsexuals have female neuron numbers in a limbic nucleus. J Clin Endocrinol Metab 2000; 85: 2034-41.

[181] Swaab DF. Handbook of clinical neurology: the human hypothalamus: basic and clinic aspects. In: Aminoff MJ, Boller F, Swaab DF, Eds. Part I: nuclei of the human hypothalamus. Amsterdam: Elsevier 2003; pp. 127-33.

[182] Swaab DF, Hofman MA. An enlarged suprachiasmatic nucleus in homosexual men. Brain Res 1990; 537: 141-8.

[183] Swaab DF. The Human hypothalamus. Basic and clinical aspects. Part II: Neuropathology of the hypothalamus and adjacent brain structures. Handbook of Clinical Neurology. Amsterdam: Elsevier $2004 b$.

[184] McEwen BS. Multiple ovarian hormone effects on brain structure and function. J Gend Specif Med 1998; 1: 33-41.
[185] McEwen BS. Estrogen actions throughout the brain. Recent Prog Horm Res 2002; 57: 357-84.

[186] Enoka RM, Stuart DG. Henneman's “size principle”. Trends Neurosci 1984; 7: 226-8.

[187] Prince KN, Prince JS, Kinghorn EW, Fleming ED, Rhees RW. Effects of sexual behavioral manipulation on brain plasticity in adult rats. Brain Res Bull 1998; 47: 349-55.

[188] Keefe DL. Sex hormones and neural mechanisms. Arch Sex Behav 2002; 31: 401-3.

[189] Genazzani AR, Monteleone P, Gambacciani M. Hormonal influence on the central nervous system. Maturitas 2002; 43 (Suppl 1): S11-7.

[190] DeVoogd T, Nottebohm F. Gonadal hormones induce dendritic growth in the adult avian brain. Science 1981; 214: 202-4.

[191] DeVoogd T, Nixdorf B, Nottebohm F. Synaptogenesis and changes in synaptic morphology related to acquisition of a new behavior. Brain Res 1985; 329: 304-8.

[192] Allen LS, Richey MF, Chai YM, Gorski RA. Sex differences in the corpus callosum of the living human being. J Neurosci 1991; 11: 933-42.

[193] Matsumoto A. Androgen stimulates neuronal plasticity in the perineal motorneurons of aged male rats. J Comp Neurol 2001; 430: 389-95.

[194] Kurz EM, Sengelaub DR, Arnold P. Androgens regulate dendritic length of mammalian motorneurons in adulthood. Science 1986; 232: 395-6.

[195] Hebbeler SL, Verhovshek T, Sengelaub. Ovariectomy attenuates dendritic growth in the hormone-sensitive spinal motorneurons. J Neurobiol 2001; 48: 301-14.

[196] Sakamoto H, Ukena K, Tsutsui K. Dendritic spine formation in response to progesterone synthesized de novo in the developing Purkinje cell in rats. Neurosci Lett 2002; 322: 111-5.

[197] Bloch GL, Gorski RA. Estrogen/progesterone treatment in adulthood affects the size of several components of the medial preoptic area in the male rat. J Comp Neurol 1988; 275: 613-22.

[198] Gould E, Woolley CS, Frankfurt M, McEwen BS. Gonadal steroids regulate dendritic spine density in hippocampal pyramidal cells in adulthood. J Neurosci 1990; 10: 1286-91.

[199] Chung WC, De Vries GJ, Swaab DF. Sexual differentiation of the bed nucleus of the stria terminalis in humans may extend into adulthood. J Neurosci 2002; 22: 1027-33.

[200] Leranth C, Roth RH, Elsworth JD, Naftolin F, Redmond DE. Estrogen is essential for maintaining nigrostriatal dopamine neurons in primates: implications for Parkinson's disease and memory. J Neurosci 2000; 20: 8604-9.

[201] Keefe D, Garcia-Segura LM, Naftolin F. New insights into estrogen action on the brain. Neurobiol Aging 1994; 15: 495-7.

[202] Mong JA, Glaser E, McCarthy MM. Gonadal steroids promote glial differentiation and alter neuronal morphology in the developing hypothalamus in a regionally specific manner. J Neurosci 1999; 19: 1464-72.

[203] Mong JA, Roberts RC, Kelly JJ, McCarthy MM. Gonadal steroids reduce the density of axonospinous synapses in the developing rat arcuate nucleus: an electron microscopy analysis. J Comp Neurol 2001; 432: 259-67.

[204] Cordero ME, Valenzuela CY, Torres R, Rodriguez A. Sexual dimorphism in number and proportion of neurons in the human median raphe nucleus. Brain Res Dev Brain Res 2000; 124: 43-52.

[205] Veliskova J, Moshe SL. Sexual dimorphism and developmental regulation of substantia nigra function. Ann Neurol 2001; 50: 596601 .

[206] Baker KG, Halliday GM, Tork I. Cytoarchitecture of the human dorsal raphe nucleus. J Comp Neurol 1990; 301: 147-61.

[207] Dean SL, McCarthy MM. Steroids, sex and the cerebellar cortex: implications for human disease. Cerebellum 2008; 7(1): 38-47.

[208] Galea LA, Spritzer MD, Barker JM, Pawluski JL. Gonadal hormone modulation of hippocampal neurogenesis in the adult. Hippocampus 2006; 16(3): 225-32.

[209] Dohanich GP. Gonadal steroids, learning and memory. In: Pfaff DW, editor. Hormones, brain, and behavior. San Diego: Academic Press 2002; vol. 2: pp. 265-327.

[210] Halpern DF, Tan U. Stereotypes and steroids: using a psychobiosocial model to understand cognitive sex differences. Brain Cogn 2001; 45: 392-414.

[211] Hausmann M. Hemispheric asymmetry in spatial attention across the menstrual cycle. Neuropsychologia 2005; 43: 1559-67. 
[212] Kaufman MJ, Levin JM, Maas LC, et al. Cocaine-induced cerebral vasoconstriction differs as a function of sex and menstrual cycle phase. Biol Psychiatry 2001; 49: 774-81.

[213] Justice AJ, de Wit H. Acute effects of D-amphetamine during the follicular and luteal phases of the menstrual cycle in women. Psychopharmacology 1999; 145: 67-75.

[214] Lynch WJ, Roth ME, Carroll ME. Biological basis of sex differences in drug abuse: preclinical and clinical studies. Psychopharmacology 2002; 164: 121-37.

[215] Teyler TJ, Vardaris RM, Lewis D, Rawitch AB. Gonadal steroids: effects on excitability of hippocampal pyramidal cells. Science 1980; 209: 1017-18.

[216] Cooke BM, Stokas MR, Woolley CS. Morphological sex differences and laterality in the prepubertal medial amygdala. $\mathbf{J}$ Comp Neurol 2007; 501(6): 904-15.

[217] Romeo RD, McCarthy JB, Wang A, Milner TA, McEwen BS. Sex differences in hippocampal estradiol-induced N-methyl-D-aspartic acid binding and ultrastructural localization of estrogen receptor- $\alpha$. Neuroendocrinology 2005; 81: 391-9.

[218] Packard M, Kohlmaier J, Alexander G. Posttraining intrahippocampal estradiol injections enhance spatial memory in male rats: interaction with cholinergic systems. Behav Neurosci 1996; 110: 626-32.

[219] Maren S, De Oca B, Fanselow MS. Sex differences in hippocampal long-term potentiation (LTP) and Pavlovian fear conditioning in rats: positive correlation between LTP and contextual learning. Brain Res1994; 661: 25-34.

[220] Van Goozen SH, Cohen-Kettenis PT, Gooren LJ, Frijda NH, Van de Poll NE. Activating effects of androgens on cognitive performance: Causal evidence in a group of female-to-male transsexuals. Neuropsychologia 1994; 32: 1153-7.

[221] Van Goozen SH, Cohen-Kettenis PT, Gooren LJ, Frijda NH, Van de Poll NE. Gender differences in behavior: activating effects of cross-sex hormones. Psychoneuroendocrinology 1995; 20: 343-63.

[222] Rose R. Hormones, behavior and psychopathology. New York: Raven 1976.

[223] Fuchs RA, Evans A, Mehta R, Case JM, See RE. Influence of sex and estrous cyclicity on conditioned cue-induced reinstatement of cocaine-seeking behavior. Psychopharmacology 2005; 179: 66272

[224] Blum D. Sex on the brain: the biological differences between men and women. New York: Penguin Press 1998.

[225] Falk D. Brain lateralization in primates and its evolution in hominids. Am J Phys Anthropol 2005; 30(S8): 107-25.

[226] Jacob LF, Gauli SJ, Sherry DF, Hoffman GE. Evolution of spatial cognition: sex-specific patterns of spatial behavior predict hippocampal size. Proc Natl Acad Sci USA 1990; 87(16): 6349-52.

[227] Zucker KJ, Bradley SJ, Oliver G, Blake J, Fleming S, Hood J. Psychosexual development of women with congenital adrenal hyperplasia. Horm Behav 1996; 30: 300-18.

[228] Byne W, Parsons B. Human sexual orientation: the biological theories reappraised. Arch Gen Psychiatry 1993; 50: 228-39.

[229] Rioult-Pedotti M, Friedman D, Donoghue JP. Learning-Induced LTP in Neocortex. Science 2000; 290(5491): 533-6.

[230] Juraska JM. Sex differences in dendritic response to differential experience in the rat visual cortex. Brain Res 1984; 295(1): 27-34.

[231] Shors T. Opposite effects of stressful experience on memory formation in males vs females. Dialogues Clin Neurosci 2002; 4 : 139-47.

[232] Klein LC, Corwin EJ. Seeing the unexpected: how sex differences in stress responses may provide a new perspective on the manifestation of psychiatric disorders. Curr Psychiatry Rep 2002; 4: 441-8.

[233] Davies W, Wilkinson LS. It is not all hormones: alternative explanations for sexual differentiation of the brain. Brain Res 2006; 1126(1): 36-45

[234] Bixo M, Backstrom T, Winblad B, Andersson A. Estradiol and testosterone in specific regions of the human female brain in different endocrine states. J Steroid Biochem Mol Biol 1995; 55: 297-303.

[235] Duff SJ, Hampson E. A sex difference on a novel spatial working memory task in humans. Brain Cogn 2001; 47: 470-93.

[236] Speck O, Ernst T, Braun J, Koch C, Miller E, Chang L. Gender differences in the functional organization of the brain for working memory. Neuroreport 2000; 11: 2581-5.
[237] Bland ST, Schmid MJ, Der-Avakian A, Watkins LR, Spencer RL, Maier F. Expression of c-fos and BDNF mRNA in subregions of the prefrontal cortex of male and female rats after acute uncontrollable stress. Brain Res 2005; 1051: 90-9.

[238] Shansky RM, Glavis-Bloom C, Lerman D, et al. Estrogen mediates sex differences in stress-induced prefrontal cortex dysfunction. Mol Psychiatry 2004; 9: 531-8.

[239] Goldman PS, Crawford HT, Stokes LP, Galkin TW, Rosvold HE. Sex-dependent behavioral effects of cerebral cortical lesions in the developing rhesus monkey. Science 1974; 186: 540-2.

[240] Tranel D, Damasio H, Denburg NL, Bechara A. Does gender play a role in functional asymmetry of ventromedial prefrontal cortex? Brain 2005; 128: 2872-81

[241] Bolla KI, Eldreth DA, Matochik JA, Cadet JL. Sex-related differences in a gambling task and its neurological correlates. Cereb Cortex 2004; 14: 1226-32.

[242] de Courten-Myers GM. The human cerebral cortex: gender differences in structure and function. J Neuropathol Exp Neurol 1999; 58(3): 217-26

[243] Rabinowicz T, Petetot JM, Gartside PS, Sheyn D, Sheyn T, de CM. Structure of the cerebral cortex in men and women. J Neuropathol Exp Neurol 2002, 61: 46-57.

[244] Barnes LL, Wilson RS, Bienias JL, Schneider JA, Evans DA, Bennett DA. Sex differences in the clinical manifestations of Alzheimer disease. Pathol Arch Gen Psychiatry 2005; 62(6): 68591

[245] Swaab DF, Chung WC, Kruijver FP, Hofman MA, Ishunina TA. Structural and functional sex differences in the human hypothalamus. Horm Behav 2001; 40: 93-8.

[246] Fleisher A, Grundman M, Jack CR Jr, et al. Sex, apolipoprotein $\varepsilon 4$ status, and hippocampal volume in mild cognitive impairment. Arch Neurol 2005; 62: 953-7.

[247] Dal Forno G, Palermo MT, Donohue JE, Karagiozis H, Zonderman $\mathrm{AB}$, Kawas $\mathrm{CH}$. Depressive symptoms, sex and risk for Alzheimer's disease. Ann Neurol 2005; 57: 381-7.

[248] Nopoulos P, Flaum M, Andreasen N. Sex differences in brain morphology in schizophrenia. Am J Psychiatry 1997; 154: 164854.

[249] Gur RE, Kohler C, Turetsky BI, et al. A sexually dimorphic ratio of orbitofrontal to amygdala volume is altered in schizophrenia. Biol Psychiatry 2004; 55: 512-7.

[250] Crow TJ. Cerebral asymmetry and the lateralization of language: core deficits in schizophrenia as pointers to the gene. Curr Opin Psychiatry 2004; 17: 96-106.

[251] Hennessy RJ, Lane A, Kinsella A, Larkin C, O'Callaghan E Waddington JL. 3D morphometrics of craniofacial dysmorphology reveals sex-specific asymmetries in schizophrenia. Schizophr Res 2004; 67: 261-8.

[252] Cowell PE, Kostianovsky DJ, Gur RC, Turetsky BI, Gur RE. Sex differences in neuroanatomical and clinical correlations in schizophrenia. Am J Psychiatry 1996; 153(6): 799-805.

[253] Feinberg I. Schizophrenia: caused by a fault in programmed synaptic elimination during adolescence? J Psychiatr Res 1982; 17: 319-34.

[254] Keshavan MS, Anderson S, Pettegrew JW. Is schizophrenia due to excessive synaptic pruning in the prefrontal cortex? The Feinberg hypothesis revisited. J Psychiatr Res 1994a; 28: 239-65.

[255] Seeman MV. Psychopathology in women and men: focus on female hormones. Am J Psychiatry 1997; 154: 641-7.

[256] Cohen RZ, Seeman MV, Gotowiec A, Kopala L. Earlier puberty as a predictor of later onset of schizophrenia in women. Am J Psychiatry 1999; 156: 1059-64.

[257] Huppi PS, Maier SE, Peled S, et al. Microstructural development of human newborn cerebral white matter assessed in vivo by diffusion tensor magnetic resonance imaging. Pediatr Res 1998; 44(4): 58490.

[258] Neil JJ, Shiran SI, McKinstry RC, et al. Normal brain in human newborns: apparent diffusion coefficient and diffusion anisotropy measured by using diffusion tensor MR imaging. Radiology 1998; 209: 57-66.

[259] Schmithorst VJ, Wilke M, Dardzinski BJ, Holland SK. Correlation of white matter diffusivity and anisotropy with age during childhood and adolescence: a cross-sectional diffusion-tensor MR imaging study. Radiology 2002; 222: 212-8.

[260] Gilmore JH, Lin W, Corouge I, et al. Early postnatal development of corpus callosum and corticospinal white matter assessed with 
quantitative tractography. American Journal of Neuroradiology 2007; 28: 1789- 95 .

[261] Becker JB. Gender differences in dopaminergic function in striatum and nucleus accumbens. Pharmacol Biochem Behav 1999; 64: 803-12.

[262] Lynch WJ, Roth ME, Carroll ME. Biological basis of sex differences in drug abuse: preclinical and clinical studies. Psychopharmacology 2002; 164: 121-37.

[263] Chaplin TM, Hong K, Bergquist K, Sinha R. Gender differences in response to emotional stress: an assessment across subjective, behavioral, and physiological domains and relations to alcohol craving. Alcohol Clin Exp Res 2008; 32(7): 1242-50.

[264] Taylor SE, Klein LC, Lewis BP, Gruenewald TL, Gurung RAR, Updegraff J A. Biobehavioral responses to stress in females: Tendand-befriend, not fight-or-flight. Psychol Rev 2000; 107: 411-29.

[265] Sapolsky RM. Stress hormones: good and bad. Neurobiol Dis 2000; 7: 540-2.

[266] Wang J, Korczykowski M, Rao $\mathrm{H}$, et al. Gender difference in neural response to psychological stress. Soc Cogn Affect Neurosci 2007; 2(3): 227-39.

[267] Bao AM, Hestiantoro A, Van Someren EJ, Swaab DF, Zhou JN. Colocalization of corticotrophin releasing hormone and oestrogen receptor-alpha in the paraventricular nucleus of the hypothalamus in mood disorders. Brain 2005; 128: 1301-13.
[268] Bao AM, Fischer DF, Wu YH, et al. A direct androgenic involvement in the expression of human corticotropin-releasing hormone. Mol Psychiatry 2006; 11: 567-76.

[269] Runmarker B, Martinsson T, Wahlstrom J, Andersen O. HLA and prognosis in multiple sclerosis. J Neurol 1994; 241: 385-90.

[270] Weinshenker BG. Natural history of multiple sclerosis. Ann Neurol 1994; 36: S6411.

[271] Beatty WW, Aupperle RL. Sex differences in cognitive impairment in multiple sclerosis. Clin Neuropsychol 2002; 16(4): 472-80.

[272] Molina JF, Drenkard C, Molina J, et al. Systemic lupus erythematosus in males. A study of 107 Latin American patients. Medicine 1996; 75: 124-30.

[273] Olsen NJ, Kovacs WJ. Gonadal steroids and immunity. Endocr Rev 1996; 17: 369-84

[274] Skuse DH. Imprinting the X-chromosome, and the male brain: Explaining sex differences in the liability to autism. Paediatr Res 2000; 47(1): 9

[275] Moir A, Jessel D. Brain sex: the real difference between men and women. New York: Dell Publishing 1989.

[276] Gurian M, Henley P, Trueman T. Boys and girls learn differently: A guide for teachers and parents. San Francisco: Jossey-Bass/John Wiley 2001.

This is an open access article licensed under the terms of the Creative Commons Attribution Non-Commercial License (http://creativecommons.org/licenses/by-nc/ $3.0 /$ ) which permits unrestricted, non-commercial use, distribution and reproduction in any medium, provided the work is properly cited. 